\title{
Tuning of Glutamate, But Not GABA, Release by an Intrasynaptic Vesicle APP Domain Whose Function Can Be Modulated by $\beta$ - or $\alpha$-Secretase Cleavage
}

\author{
Wen Yao, ${ }^{1 *}$ Marc D. Tambini, ${ }^{1 *}$ Xinran Liu, ${ }^{2}$ and $\oplus^{-L u c i a n o} D^{\prime}$ Adamio ${ }^{1}$ \\ ${ }^{1}$ Department of Pharmacology, Physiology and Neuroscience, New Jersey Medical School, Brain Health Institute, State University of New Jersey, Newark, \\ New Jersey 07103, and 2Department of Cell Biology, Yale University School of Medicine, New Haven, Connecticut 06510
}

APP, whose mutations cause familial Alzheimer's disease (FAD), modulates neurotransmission via interaction of its cytoplasmic tail with the synaptic release machinery. Here we identified an intravesicular domain of APP, called intraluminal SV-APP interacting domain (ISVAID), which interacts with glutamatergic, but not GABAergic, synaptic vesicle proteins. ISVAID contains the $\beta$ - and $\alpha$-secretase cleavage sites of APP: proteomic analysis of the interactome of ISVAID suggests that $\beta$ - and $\alpha$-secretase cleavage of APP cuts inside the interaction domain of ISVAID and destabilizes protein-protein interactions. We have tested the functional significance of the ISVAID and of $\beta$-/ $\alpha$-secretase-processing of APP using various ISVAID-derived peptides in competition experiments on both female and male mouse and rats hippocampal slices. A peptide encompassing the entire ISVAID facilitated glutamate, but not GABA, release acting as dominant negative inhibitor of the functions of this APP domain in acute hippocampal slices. In contrast, peptides representing the product of $\beta$ - $/ \alpha$-secretase-processing of ISVAID did not alter excitatory neurotransmitter release. These findings suggest that cleavage of APP by either $\beta$ - or $\alpha$-secretase may inactivate the ISVAID, thereby enhancing glutamate release. Our present data support the notion that APP tunes glutamate release, likely through intravesicular and extravesicular interactions with synaptic vesicle proteins and the neurotransmitter release machinery, and that $\beta$-/ $\alpha$ cleavage of APP facilitates the release of excitatory neurotransmitter.

Key words: Alzheimer disease; APP; GABA; glutamate; secretases; synaptic vesicles

Significance Statement

Alzheimer's disease has been linked to mutations in APP. However, the biological function of APP is poorly understood. Here we show that an intravesicular APP domain interacts with the proteins that control the release of glutamate, but not GABA. Interfering with the function of this domain promotes glutamate release. This APP domain contains the sites cleaved by $\beta$-and $\alpha$-secretases: our data suggest that $\beta$-/ $\alpha$ cleavage of APP inactivates this functional APP domain promoting excitatory neurotransmitter release.

\section{Introduction}

APP is a Type I membrane protein that undergoes complex proteolysis. In the amyloidogenic proteolytic cascade, APP is cleaved by $\beta$-secretase/BACE1 into sAPP $\beta$ and the COOH-terminal fragment $\beta$ CTF. Cleavage of $\beta$ CTF by $\gamma$-secretase produces $A \beta$ pep-

\footnotetext{
Received Nov. 20, 2018; revised May 17, 2019; accepted May 21, 2019.

Author contributions: W.Y., M.D.T., X.L., and L.D. designed research; W.Y., M.D.T., X.L., and L.D. performed research;W.Y., M.D.T., and L.D. edited the paper; L.D. analyzed data; L.D. wrote the first draft of the paper; L.D. wrote the paper.

This work was supported by National Institutes of Health Grant R01AG952286, R01AG033007, R21AG048971, and R01AG063407 to L.D.

L.D. and W.Y. are inventors on U.S. Provisional Patent Application Number 62/831,287, which includes ISVAID. The remaining authors declare no competing financial interests.

*W.Y. and M.D.T. contributed equally to this work.

Correspondence should be addressed to Luciano D’Adamio at luciano.dadamio@rutgers.edu.

https://doi.org/10.1523/JNEUROSCI.0207-19.2019

Copyright $\odot 2019$ the authors
}

tides and the intracellular domain (AID/AICD). Alternatively, APP is processed by $\alpha$-secretase into $\operatorname{sAPP} \alpha$ and the $\mathrm{COOH}$ terminal fragment $\alpha \mathrm{CTF}$. $\alpha \mathrm{CTF}$ can be cleaved by $\gamma$-secretase to produce P3 and AID/AICD (Passer et al., 2000; Sisodia et al., 2001; Sisodia and St George-Hyslop, 2002). Another pathway involves cleavage of the cytoplasmic region of APP by caspases (Gervais et al., 1999; Pellegrini et al., 1999). Processing of fulllength APP generates a membrane-bound $\mathrm{NH}_{2}$-terminal fragment called APP-Ncas and a COOH-terminal intracellular peptide called APP-Ccas, whereas caspase cleavage of AID/AICD splits the cytoplasmic domain of APP into two soluble cytosolic peptides: the aforementioned Ccas and the $\mathrm{NH}_{2}$-terminal fragment JCasp (see Fig. 1B).

APP processing has a central role in both familial Alzheimer disease (FAD) and sporadic Alzheimer disease (SAD) forms of $\mathrm{AD}$ and related dementias. Mutations in $A P P$ and in genes that 
regulate APP processing, such as the $\gamma$-secretase components PSEN1/PSEN2 and BRI2/ITM2B, cause FAD and the AD-like familial British dementia and familial Danish dementia (Matsuda et al., 2005, 2008, 2011a,b; Giliberto et al., 2009; Garringer et al., 2010; Tamayev et al., 2010a,b, 2011, 2012b; De Strooper and Voet, 2012). Increased BACE1 expression/activity and BACE1 gene polymorphisms are associated with SAD (Jo et al., 2008; Hampel and Shen, 2009; Cheng et al., 2014; Long et al., 2014); loss-of-function mutation in genes coding for proteins with $\alpha$-secretase activity are associated with SAD (Suh et al., 2013; Hartl et al., 2018). This genetic evidence, coupled to the identification of $\mathrm{A} \beta$ as the main component of senile plaques, provides the foundation for the "amyloid hypothesis," which states, briefly, that $\mathrm{A} \beta$ is the toxic metabolite responsible for neurodegeneration in $\mathrm{AD}$. Accordingly, many research efforts have been focused on the mechanism of $A \beta$-mediated toxicity and factors that drive the amyloidogenic pathway. Yet, there is some evidence for biological activities of non-A $\beta$ APP metabolites. AID/AICD modulates apoptosis and gene transcription (Passer et al., 2000; Cao and Südhof, 2004; Checler et al., 2007). Ccas and JCasp (Lu et al., 2000; Madeira et al., 2005) also possess toxic activities. JCasp interferes with the ability of APP to bind presynaptic proteins and reduces glutamate release (Fanutza et al., 2015). A $\beta$ both regulates normal synaptic transmission and prompts deficits in synaptic plasticity (Puzzo and Arancio, 2006; Shankar et al., 2007; Puzzo et al., 2008, 2017; Fogel et al., 2014; Gulisano et al., 2018). $\operatorname{sAPP} \alpha$ has neurotrophic functions and is involved in synaptic plasticity (Milosch et al., 2014). sAPP $\beta$ promotes axon pruning and neurodegeneration (Nikolaev et al., 2009). $\beta$ CTF mediates long-term synaptic plasticity deficits, behavioral deficits, and neurodegeneration (Oster-Granite et al., 1996; Tamayev and D'Adamio, 2012; Tamayev et al., 2012b).

Given the variety of cleavage events that occur in the intraluminal-extracellular juxta-membranous region of APP, we postulated the existence of a functional domain of APP that is regulated by these cleavages. A pulldown approach was used to examine what putative interactions were abolished by APP cleavage and what new interactions were created by the neoepitopes formed from the resulting APP fragments. Specifically, we focused on the binding sites abolished by $\beta$ and $\alpha$ cleavage of APP, and the new binding sites formed by the $\mathrm{NH}_{2}$-termini of $\alpha \mathrm{CTF}$ and $\beta C T F$ (see Fig. 1A). Here, we describe the binding of synaptic vesicle (SV) machinery to this APP domain containing the $\beta$ and $\alpha$ cleavage sites.

\section{Materials and Methods}

Mice, rats, and ethics statement. Mice and rats were handled according to the Ethical guidelines for treatment of laboratory animals of the National Institutes of Health. The procedures were described and approved by the Institutional Animal Care and Use Committee. The App-KO (stock \#004133) mice were originally purchased from The Jackson Laboratory on a C57BL/6J background. Mice were crossed to 129 mice to generate $A p p-K O / h e t e r o z y g o u s$ animals; $A p p-K O / h e t e r o z y g o u s$ mice were crossed to obtain the WT and App-KO littermates used in the experiments described in Figure 2. The WT mice obtained from these breeding were used for generating material for proteomic experiments and for performing the experiments described in Figures 3, 4, and 5. In all cases, an equal number of male and female mice were used. The rats used were Long-Evans rats.

Mouse brain preparation. Brains were homogenized (w/v $=100 \mathrm{mg}$ tissue/ $1 \mathrm{ml}$ buffer) in $320 \mathrm{~mm}$ sucrose, $20 \mathrm{~mm}$ Tris base, $\mathrm{pH}$ 7.4, $1 \mathrm{~mm}$ EDTA (HB) plus protease and phosphatase inhibitors (Thermo Fisher Scientific). Homogenates were centrifuged at $800 \times g$ for $10 \mathrm{~min}$. Supernatant were centrifuged at $9200 \times g$ for $10 \mathrm{~min}$ to obtain the pellet (P2) and the supernatant (S2) fractions. The P2 fraction, which contains synaptosomes (SPs), was solubilized in $0.32 \mathrm{M}$ sucrose, $20 \mathrm{~mm}$ Tris base, $\mathrm{pH}$ 7.4, $1 \mathrm{~mm}$ EDTA, incubated for $30 \mathrm{~min}$ at $4^{\circ} \mathrm{C}$, and centrifuged at $21,000 \times g$ for $15 \mathrm{~min}$. The supernatant (LS1) was collected. The S2 and LS1 fractions were combined and used for the proteomic experiments.

Pull-down assays with St-APP peptides and Western blot analysis. The APP peptides with a $\mathrm{COOH}$-terminal strep-tag were immobilized on StrepTactin column (IBA), incubated with StrepTactin precleared S2 and LS1 fractions, washed, and eluted with desthiobiotin. For the Western blot analysis shown in Figure $1 C, 1 \mu \mathrm{g}$ of protein from each eluate was brought to $15 \mu$ l with PBS, LDS sample buffer-10\% $\beta$-mercaptoethanol (Invitrogen, NP0007), $8 \mathrm{M}$ urea, denatured for $30 \mathrm{~min}$ at $55^{\circ} \mathrm{C}$, cooled on ice, and loaded on a $4 \%-12 \%$ Bis-Tris polyacrylamide gel (Bio-Rad, 3450125). Proteins were transferred onto nitrocellulose at $25 \mathrm{~V}$ for $7 \mathrm{~min}$ using the Trans-blot Turbo system (Bio-Rad) and visualized by red Ponceau staining. Membranes were blocked $30 \mathrm{~min}$ in 5\% milk (Bio-Rad, 1706404), washed extensively in PBS/Tween $200.05 \%$, and primary antibody was applied overnight at $4^{\circ} \mathrm{C}$ at 1:1000 dilution in blocking solution (Thermo Fisher Scientific, 37573). The following antibodies were used: VAMP2 (Synaptic Systems, rabbit polyclonal antibody 104202), vGlut1 (Synaptic Systems, rabbit polyclonal antibody 135303), synaptotagmin-1 (D33B7), rabbit mAb (Cell Signaling Technology, \#14558), synaptophysin (D35E4) rabbit mAb (Cell Signaling Technology, \#5461). A 1:1 mix of HRP-linked anti-rabbit (SouthernBiotech, OB405005) and anti-rabbit (Cell Signaling Technology, 7074), were diluted 1:1000 in 5\% milk and used against rabbit primary antibodies for $60 \mathrm{~min}$ at room temperature with shaking. Blots were developed with West Dura ECL reagent (Thermo Fisher Scientific, PI34076) and visualized on a ChemiDoc MP Imaging System (Bio-Rad).

Mass spectrometry. The following analysis was performed by MSBioworks. To prepare samples for mass spectrometry, the volume of each sample was reduced to $50 \mu \mathrm{l}$ by vacuum centrifugation, $20 \mu \mathrm{l}$ of each concentrated sample was processed by SDS-PAGE using a 10\% Bis-Tris NuPAGE gel (Invitrogen) with the 2-(N-morpholino)ethanesulfonic acid buffer system. The gel was run $\sim 2 \mathrm{~cm}$. The mobility region was excised into 10 equal sized segments, and in-gel digestion was performed on each using a robot (ProGest, DigiLab) with the following protocol: washed with $25 \mathrm{~mm}$ ammonium bicarbonate followed by acetonitrile, reduced with $10 \mathrm{~mm}$ DTT at $60^{\circ} \mathrm{C}$ followed by alkylation with $50 \mathrm{~mm}$ iodoacetamide at room temperature, digested with trypsin (Promega) at $37^{\circ} \mathrm{C}$ for $4 \mathrm{~h}$, quenched with formic acid, and the supernatant was analyzed directly without further processing. Each digest was analyzed by nano-liquid chromatography tandem mass spectrometry (LC-MS/MS) with a Waters NanoAcquity HPLC system interfaced to a Thermo Fisher Scientific Q Exactive mass spectrometer. Peptides were loaded on to a trapping column and eluted over a $75 \mathrm{~mm}$ analytical column at 350 $\mathrm{nl} / \mathrm{min}$; both columns were packed with Jupiter Proteo resin (Phenomenex). The mass spectrometer was operated in data-dependent mode, with MS and MS/MS performed in the Orbitrap at 70,000 and 17,500 FWHM resolution, respectively. The 15 most abundant ions were selected for MS/MS.

Fractionation of brain lysates and Western blot analysis. For brain fractionation, we adapted the procedure described by Peng et al. (2004). Briefly, four mouse cortices were homogenized with a glass-Teflon homogenizer in buffer A (5 mM HEPES, pH 7.4, $1 \mathrm{~mm} \mathrm{MgCl}_{2}, 0.5 \mathrm{~mm}$ $\mathrm{CaCl}_{2}$ ), and protease/phosphatase inhibitor (Thermo Fisher Scientific, 78440 ), with all steps done at $4^{\circ} \mathrm{C}$. Homogenate was spun at $1400 \times g$ for $10 \mathrm{~min}$, and the supernatant was collected and labeled S1. S1 was spun at $13,800 \times g$ for $10 \mathrm{~min}$, and the supernatant was collected and labeled S2. The pellet, P2, was resuspended in $300 \mu \mathrm{l}$ buffer B ( $0.32 \mathrm{M}$ sucrose, $6 \mathrm{~mm}$ Tris, $\mathrm{pH} 8.0)$, layered a discontinuous sucrose gradient $(0.85,1.0$, and 1.2 $\mathrm{M}$ in $6 \mathrm{~mm}$ Tris, $\mathrm{pH} 8.0$ ), and spun for $2 \mathrm{~h}$ at $83,000 \times \mathrm{g}$ in a swinging bucket rotor. SPs were present in a band at the $1.0 / 1.2 \mathrm{M}$ interface. The SP fraction was brought up to $1 \mathrm{ml}$ with buffer $\mathrm{B}$ and was added to $1 \mathrm{ml} 1 \%$ Triton X-100, $6 \mathrm{~mm}$ Tris, and mixed for $15 \mathrm{~min}$. Samples were spun at $32,800 \times g$ for $20 \mathrm{~min}$. The resulting pellet (the Triton X-100 insoluble fraction [TIF]) was resuspended in $40 \mu \mathrm{l}$ PBS, and the supernatant was labeled Triton X-100 soluble fraction (TSF). For Western blot analysis, $15 \mu \mathrm{g}$ of protein from each fraction (S1, S2, SP, P2, TIF, and TSF) was 
brought to $15 \mu \mathrm{l}$ with PBS and LDS sample buffer-10\% $\beta$-mercaptoethanol (Invitrogen, NP0007) and $8 \mathrm{M}$ urea, denatured for $30 \mathrm{~min}$ at $55^{\circ} \mathrm{C}$, cooled on ice, and loaded on a $4 \%-12 \%$ Bis-Tris polyacrylamide gel (Bio-Rad, 3450125). Proteins were transferred onto nitrocellulose at $25 \mathrm{~V}$ for $7 \mathrm{~min}$ using the Trans-blot Turbo system (Bio-Rad) and visualized by red Ponceau staining. Membranes were blocked $30 \mathrm{~min}$ in 5\% milk (Bio-Rad, 1706404), washed extensively in PBS/Tween-20 0.05\%, and primary antibody was applied overnight at $4^{\circ} \mathrm{C}$ at 1:1000 dilution in blocking solution (Thermo Fisher Scientific, 37573). The following antibodies were used: Y188 (APP-C terminus, Abcam, ab32136), synaptophysin (D35E4) rabbit mAb (Cell Signaling Technology, \#5461), PSD95 rabbit polyclonal antibody (Cell Signaling Technology, \#2507), presenilin 1 (D39D1) rabbit mAb (Cell Signaling Technology, \#5643), NSF rabbit polyclonal (Synaptic Systems, 123002), Stx1bp1 rabbit polyclonal (Synaptic Systems, 116002), Stx1b rabbit polyclonal (Synaptic Systems, 110402), Snap25 rabbit polyclonal (Synaptic Systems, 111002), Vglut1 rabbit polyclonal (Synaptic Systems, 135303), Vgat mouse monoclonal (Synaptic Systems, 131003), SV2a mouse monoclonal (Synaptic Systems, 119011), Sv2b mouse monoclonal (Synaptic Systems, 119111), Sv2c rabbit polyclonal (Synaptic Systems, 119203), Nicastrin rabbit mAb (Cell Signaling Technology, \#5665), Bace1 rabbit mAb (Cell Signaling Technology, \#5606, \#2507), NMDA receptor 2B (GluN2B) (D15B3) rabbit $\mathrm{mAb}$ (Cell Signaling Technology, \#4212), and anti-mouse (SouthernBiotech, OB103105) and a 1:1 mix of anti-rabbit (SouthernBiotech, OB405005) and anti-rabbit (Cell Signaling Technology, 7074) were diluted 1:1000 in 5\% milk and used against mouse and rabbit primary antibodies for $30 \mathrm{~min}$ at room temperature with shaking. Blots were developed with West Dura ECL reagent (Thermo Fisher Scientific, PI34076) and visualized on a ChemiDoc MP Imaging System (Bio-Rad).

Immunoelectron microscopy. Mouse brains were cut by a vibratome; the cerebral cortex regions from sections $(200 \mu \mathrm{m})$ were punched out and high-pressure frozen with a Leica Microsystems EM HPM100 at 2100 psi. Frozen samples were subsequently freeze-substituted in a Leica Microsystems freeze-substitution unit (AFS2) and embedded in HM20 resin; $60 \mathrm{~nm}$ sections were cut using a Leica Microsystems UC7 Ultramicrotome and collected on formvar/carbon-coated grids. For immunolabeling, grids were incubated with a monoclonal antibody against human APP C terminus Y188 (Abcam) at 1:150 dilution overnight, followed by rinsed in PBS, then incubated with $10 \mathrm{~nm}$ protein A gold (Utrecht UMC) for $30 \mathrm{~min}$. The grids were well rinsed in PBS, fixed in 1\% glutaraldehyde for $5 \mathrm{~min}$, and stained in $2 \%$ aqueous uranyl acetate and lead citrate. The labeled sections were examined by a FEI Tecnai Biotwin TEM at accelerating voltage of $80 \mathrm{kV}$. Digital Images were recorded by a Morada CCD camera and iTEM (Olympus) imaging software.

Immunofluorescent microscopy. Mice were anesthetized by isoflurane inhalation and perfused with ACSF. Brains were extracted and sectioned to $100 \mu \mathrm{m}$ thickness by vibratome. Free-floating slices were incubated for $3 \mathrm{~h}$ at $30^{\circ} \mathrm{C}$ in ACSF alone or ACSF with $10 \mu \mathrm{M}$ FITC-Ex/TM peptide. Slices were washed with PBS and fixed for $30 \mathrm{~m}$ in $4 \%$ PFA. Fixed slices were then washed again and incubated for $90 \mathrm{~min}$ with blocking solution ( $10 \%$ normal goat serum, $0.02 \%$ saponin, and $0.1 \%$ Triton, in PBS, pH 7.4). Slices were incubated overnight at $4^{\circ} \mathrm{C}$ with anti-Vamp2 (1:200, Synaptic Systems, 104202) in blocking solution (Vamp2 staining not shown in figure). After three washes with PBS, slices were incubated with Alexa-594 anti-rabbit fluorescent secondary antibody (Thermo Fisher Scientific) at room temperature for $2.5 \mathrm{~h}$. After three washes with PBS, slices were mounted on glass slides in DAPI Fluoromount-G (SouthernBiotech). Hippocampi were visualized using a A1R confocal microscope (Nikon) under $63 \times$ magnification.

Brain slice preparation. Mice and rats were deeply anesthetized with isoflurane and intracardially perfused with an ice-cold cutting solution containing the following (in $\mathrm{mM}$ ): 120 choline chloride, $2.6 \mathrm{KCl}, 26$ $\mathrm{NaHCO}_{3}, 1.25 \mathrm{NaH}_{2} \mathrm{PO}_{4}, 0.5 \mathrm{CaCl}_{2}, 7 \mathrm{MgCl}_{2}, 1.3$ ascorbic acid, 15 glucose, prebubbled with $95 \% \mathrm{O}_{2} / 5 \% \mathrm{CO}_{2}$ for $15 \mathrm{~min}$. The brains were rapidly removed from the skull. Coronal brain slices containing the hippocampal formation ( $350 \mu \mathrm{m}$ thick) were prepared in the ice-cold cutting solution bubbled with $95 \% \mathrm{O}_{2} / 5 \% \mathrm{CO}_{2}$ using Vibratome VT1200S (Leica Microsystems) and then incubated in an interface chamber in ACSF containing the following (in mM): $126 \mathrm{NaCl}, 3 \mathrm{KCl}, 1.2 \mathrm{NaH}_{2} \mathrm{PO}_{4}$,
$1.3 \mathrm{MgCl}_{2}, 2.4 \mathrm{CaCl}_{2}, 26 \mathrm{NaHCO}_{3}$, and 10 glucose, $\mathrm{pH} 7.3$, bubbled with $95 \% \mathrm{O}_{2} / 5 \% \mathrm{CO}_{2}$ at $30^{\circ} \mathrm{C}$ for $1 \mathrm{~h}$ and then kept at room temperature. The hemi-slices were transferred to a recording chamber perfused with ACSF at a flow rate of $\sim 2 \mathrm{ml} / \mathrm{min}$ using a peristaltic pump. Experiments were performed at $28.0 \pm 0.1^{\circ} \mathrm{C}$.

Whole-cell electrophysiological recording. Whole-cell recordings in the voltage-clamp mode $(-70 \mathrm{mV})$ were made with patch pipettes containing the following (in mM): 132.5 Cs-gluconate, $17.5 \mathrm{CsCl}, 2 \mathrm{MgCl}_{2}, 0.5$ EGTA, 10 HEPES, 4 ATP, and 5 QX-314, with $\mathrm{pH}$ adjusted to 7.3 by $\mathrm{CsOH}$. Basal synaptic responses were evoked at $0.05 \mathrm{~Hz}$ by electrical stimulation of the Schaffer collateral afferents using concentric bipolar electrodes. EPSCs were recorded in ACSF containing $15 \mu \mathrm{m}$ bicuculline methiodide to block GABA-A receptors. For recording of paired-pulse ratio, paired-pulse stimuli with 50 or $200 \mathrm{~ms}$ interpulse interval were given. The paired-pulse ratio was calculated as the ratio of the second EPSC amplitude to the first. For recording of AMPA/NMDA ratio, the membrane potential was held at $-70 \mathrm{mV}$ to record only AMPAR current; then the membrane potential was turned to $40 \mathrm{mV}$ to record NMDAR current. mEPSCs were recorded by maintaining neurons at $-70 \mathrm{mV}$ with ACSF containing $1 \mu \mathrm{M}$ TTX and $15 \mu \mathrm{M}$ bicuculline methiodide to block action potentials and GABA-A receptors, respectively, and analyzed using mini Analysis Program. mIPSCs were recorded with patch pipettes containing the following (in $\mathrm{mM}$ ): $135 \mathrm{KCl}, 2 \mathrm{MgCl}_{2}, 0.1$ EGTA, 10 HEPES, $2 \mathrm{Na}_{2}$ ATP, $0.2 \mathrm{Na}_{2} \mathrm{GTP}$, pH 7.3 (osmolarity 290-310 mOsm) with $1 \mu \mathrm{M}$ TTX and AMPA receptor antagonist NBQX (10 $\mu \mathrm{M}$, Tocris Bioscience) in perfusing ACSF. For AMPA input-output curves, the membrane potential was held at $-70 \mathrm{mV}$, and the stimulus intensity was raised from $0.1 \mathrm{~mA}$ in steps of $100 \mu \mathrm{A}$. EPSCs were recorded for 5 min with $20 \mathrm{~s}$ interval at each stimulation intensity. Data were collected and analyzed using the Axopatch 700B amplifiers and pCLAMP10 software (Molecular Devices).

Experimental design and statistical analysis. The brain lysates for proteomic experiments were obtained from 3- to 4- month-old female and male mice ( 4 each). The slices used for electrophysiology studies were obtained from 2- to 3-month-old mice and 6- to 8-week-old rats. The recordings shown in Figure 4 were obtained from 5 male and 5 female mice for each genotype (WT and App-KO). For the experiments shown in Figure 5, we used the following: (1) 9 females and 9 males for the control group C; (2) 7 females and 7 males for the Ex/TM $1 \mu \mathrm{M}$ group; (3) 9 females and 9 males for the Ex/TM 100 nm group; and (4) 6 females and 6 males for the $\beta / \mathrm{TM}, \mathrm{EX} / \beta$, and $\mathrm{Ex} / \alpha$ groups. The recordings shown in Figure 6 were obtained from 3 male and 3 female mice (one recording with Ex/TM and one recording with vehicle alone from each animal). The recordings shown in Figure $7 A$ were obtained from 5 male and 5 female rats (one recording with Ex/TM and one recording with vehicle alone, when possible, from each animal). The recordings shown in Figure $7 B$ were obtained from 4 male and 4 female rats (one recording with Ex/TM and one recording with vehicle alone, when possible, from each animal).

Statistical significance was evaluated using the following: (1) ordinary one-way ANOVA followed by post hoc Tukey's multiple-comparisons test when applicable (i.e., when the ordinary one-way ANOVA test showed statistical significance) for experiments shown in Figures 4 and 5; (2) two-way repeated-measures ANOVA followed by post hoc Tukey's multiple-comparisons test for experiments shown in Figure 6; and (3) unpaired $t$ test for experiments shown in Figure 7A, B. Statistical analysis was performed with GraphPad Prism version 8 for Mac. Significant differences were accepted at $p<0.05$.

\section{Results}

Identification of an intraluminal SV-APP interacting domain (ISVAID) containing the $\boldsymbol{\beta}$ - and $\boldsymbol{\alpha}$-secretase cleavage sites

To test whether APP processing by $\beta$ - and $\alpha$-secretases changes the interactome of APP, we used a proteomic approach (Zhou et al., 2004; Del Prete et al., 2014). Four synthetic peptides were created: St (control Strep-tag peptide), $\alpha /$ TM-St, $\beta^{\prime} / \mathrm{TM}-\mathrm{St}$, and $\beta / \mathrm{TM}-\mathrm{St}$, which correspond to the sequence between each re- 


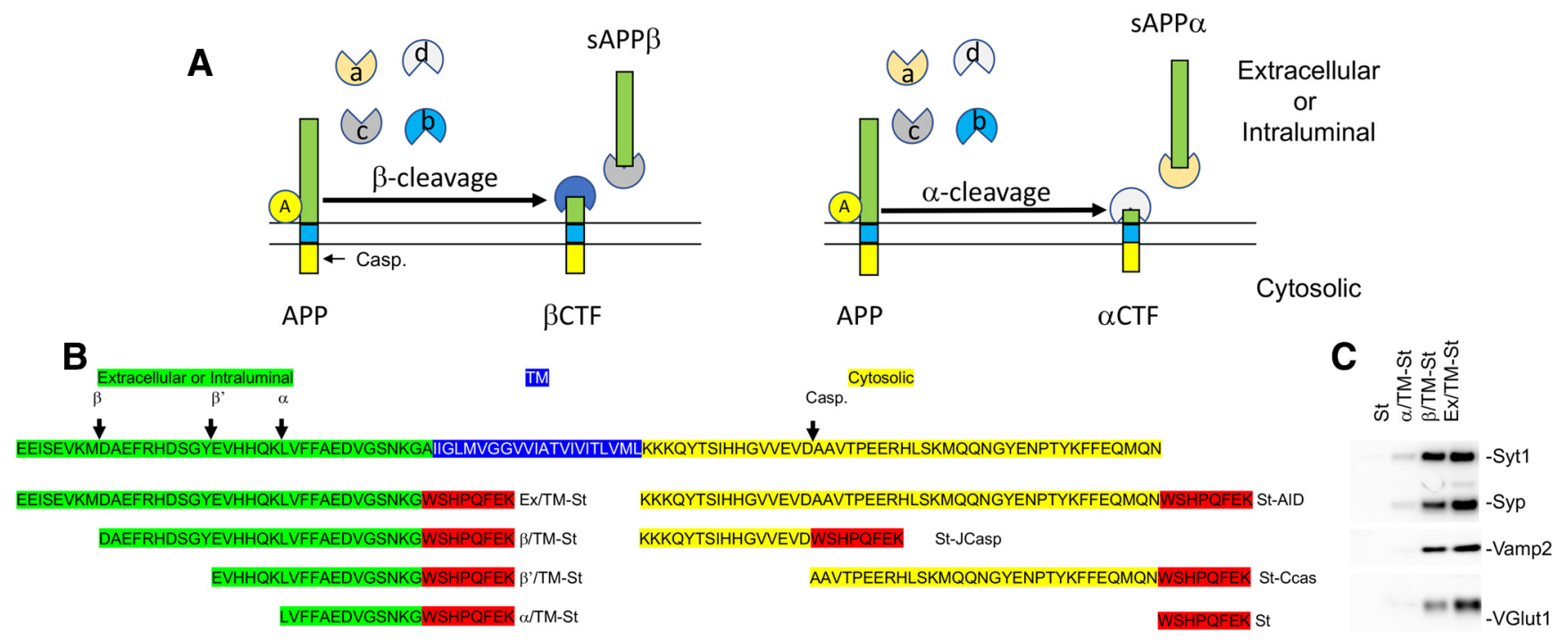

Figure 1. The intraluminal APP-SV interactome. $A, \beta$ - and/or $\alpha$-secretases may: (1) destroy a binding domain of APP, thereby downregulating interaction with putative binding partners, schematically represented as A; and (2) generate APP metabolites, $\operatorname{SAPP} \beta, \operatorname{sAPP} \alpha, \alpha$ CTF, and $\beta C T F$, with new docking sites for proteins, schematically represented as a-d, which do not interact with full-length APP. $B$, Baits used for the proteomic experiments shown in this manuscript. Casp. indicates the caspase cleavage site present in the cytosolic tail of APP. $\beta$ and arrow, $\beta^{\prime}$ and arrow indicate the two cleavage sites of APP by $\beta$-secretase; $\alpha$ and arrow indicates the cleavage site of APP by $\alpha$-secretase. C, Brain lysates were affinity purified on StrepTactin columns bound to the indicated St peptides. Bound proteins were analyzed by Western blot. Syp, Vamp2, Syt1, and Vglut1 bound APP-derived baits with this quantitative order: Ex/TM-St $>\beta / T M-S t$ [tmt] $\alpha / T M-S t$. None of these four proteins bounds the negative control peptide St.

spective cleavage site and the start of the transmembrane domain followed by a Strep-tag (Fig. 1B). These peptides were immobilized on StrepTactin resin. Mouse brain fractions were precleared on StrepTactin resin columns and applied in parallel on separate columns packed with StrepTactin-St-, StrepTactin- $\alpha /$ TM-St-, StrepTactin- $\beta^{\prime} /$ TM-St-, or StrepTactin- $\beta /$ TM-St-coated resin. After extensive washes, the St, $\alpha / \mathrm{TM}-\mathrm{St}, \beta^{\prime} / \mathrm{TM}-\mathrm{St}$, and $\beta / \mathrm{TM}-\mathrm{St}$ peptides and any potential interactors were eluted with desthiobiotin. Eluted proteins were digested with trypsin and identified by nano-LC-MS/MS. This analysis showed that $\beta$ CTF-St brings down 33 integral SV proteins (including all subunits of the vacuolar proton ATPase, the vesicular-SNARE Vamp2 and Vamp1, and the $\mathrm{Ca}^{2+}$ sensors Synaptotagmin-1, Synaptotagmin-2), and 12 proteins associated with the outer membrane of SV or interacting with SV (including AP-2 subunits, the target membrane SNAREs Syntaxin-1b, Syntaxin-1a, the cytosolic SNARE Snap25, Syntaxin-binding protein $1, \mathrm{Nsf}$, and $\alpha / \beta$-Snaps) (Table 1 ). Eleven and 8 of the $45 \mathrm{SV}$-related proteins interacting with $\beta / \mathrm{TM}-\mathrm{St}$ did not bind $\alpha / \mathrm{TM}-\mathrm{St}$ or $\beta^{\prime} / \mathrm{TM}-\mathrm{St}$, respectively. The others (34 for $\alpha /$ TM-St and 37 for $\beta^{\prime} /$ TM-St) were less abundant in $\alpha /$ TM-St and $\beta^{\prime} /$ TM-St-St compared with $\beta /$ TM-St pulldowns (Table 1). Overall, abundance of synaptic vesicle-related proteins followed this order: $\beta /$ TM-St $\gg \beta^{\prime} /$ TM-St $>\alpha /$ TM-St.

Next, we tested whether adding more APP residues $\mathrm{NH}_{2}-$ terminal to the $\beta$ cleavage site would result in stronger binding to SV proteins. To this end, we synthesized Ex/TM-St, which consists of the extracellular/intraluminal region of APP spanning 8 amino acids $\mathrm{NH}_{2}$-terminal to the $\beta$ cleavage site fused to the $\mathrm{St}$ peptide at the $\mathrm{COOH}$ terminus (Fig. $1 B$ ), and performed a pulldown experiment as above. As shown in Table 2, the same SVrelated proteins were pulled down, following this quantitative order: Ex/TM-St $>\beta /$ TM-St [tmt] $\alpha /$ TM-St. Western analysis of the eluate confirmed the proteomic data, as Synaptotagmin 1 (Syn1), Synaptophysin (Syp), Vamp2, and the Vesicular glutamate transporter 1 (VGlut1) were readily detected in Ex/TM-Stbut not in St control pull-downs (Fig. 1C). Consistent with the proteomic data, the signals for these proteins were reduced in $\beta /$ TM-St and almost absent in $\alpha /$ TM-St pull-downs. The data suggest that APP could establish an intraluminal SV-APPinteracting network via the direct interaction of the ISVAID juxtaposed to the vesicular membrane with some yet to be identified SV protein. The other components are most likely indirectly associated with APP.

\section{In synapses, APP is predominantly localized in SVs}

For this intravesicular interactome of APP with SV proteins to have biological relevance, APP must be present in SVs in vivo. Albeit the localization of APP in SVs is well established (Groemer et al., 2011; Del Prete et al., 2014), we performed further tests to validate our interactome findings. First, SPs isolated from murine brain cortex were fractionated into a TIF and a TSF. The TIF was enrichment of PSD95 and Nmdar2b (Fig. 2A), two postsynaptic density fraction proteins that are Triton X-100 insoluble. The TSF vas enriched in SV proteins, such as Syp, SV2A, SV2B, SV2C, Vamp2, VGlut1, and vesicular inhibitory amino acid transporter (VIAAT), as well as the target membrane SNAREs Syntaxin-1b (Stx1b), the cytosolic SNARE Snap25, Syntaxin-binding protein 1 (Stxbp1), and Nsf (Fig. 2A). It is worth noting that a small amount of SV proteins were found in the TIF: since docked SV docked at the presynaptic termini can copurify with the Triton $\mathrm{X}-100$ insoluble active zone, it is possible that these signals may come from the ready-to-go SV pool present in the active zone isolated in the TIF. APP, both the full-length precursor and C-terminal fragments, was mainly present in the TSF of with a small fraction in TIF fraction, just like SV proteins and proteins associated with SV exocytosis. PS1 and Nicastrin (Nct), the catalytic component and structural component of $\gamma$-secretase, respectively, as well as $\beta$-secretase had a similar distribution to APP (Fig. 2A). The finding that APP and proteins found in the Ex/ TM-St interactome cosediment in similar fractions supports the biological relevance of this interactome.

The localization of APP in SVs is well established (Groemer et al., 2011; Del Prete et al., 2014). To confirm these findings, we used I-EM to localize APP at hippocampal CA1 synapses. We 
Table 1. List of integral SV proteins and proteins associated with SV that were included in the $\alpha / \mathrm{TM}, \boldsymbol{\beta}^{\prime} / \mathrm{TM}$, and $\boldsymbol{\beta} / \mathrm{TM}$-interactomes

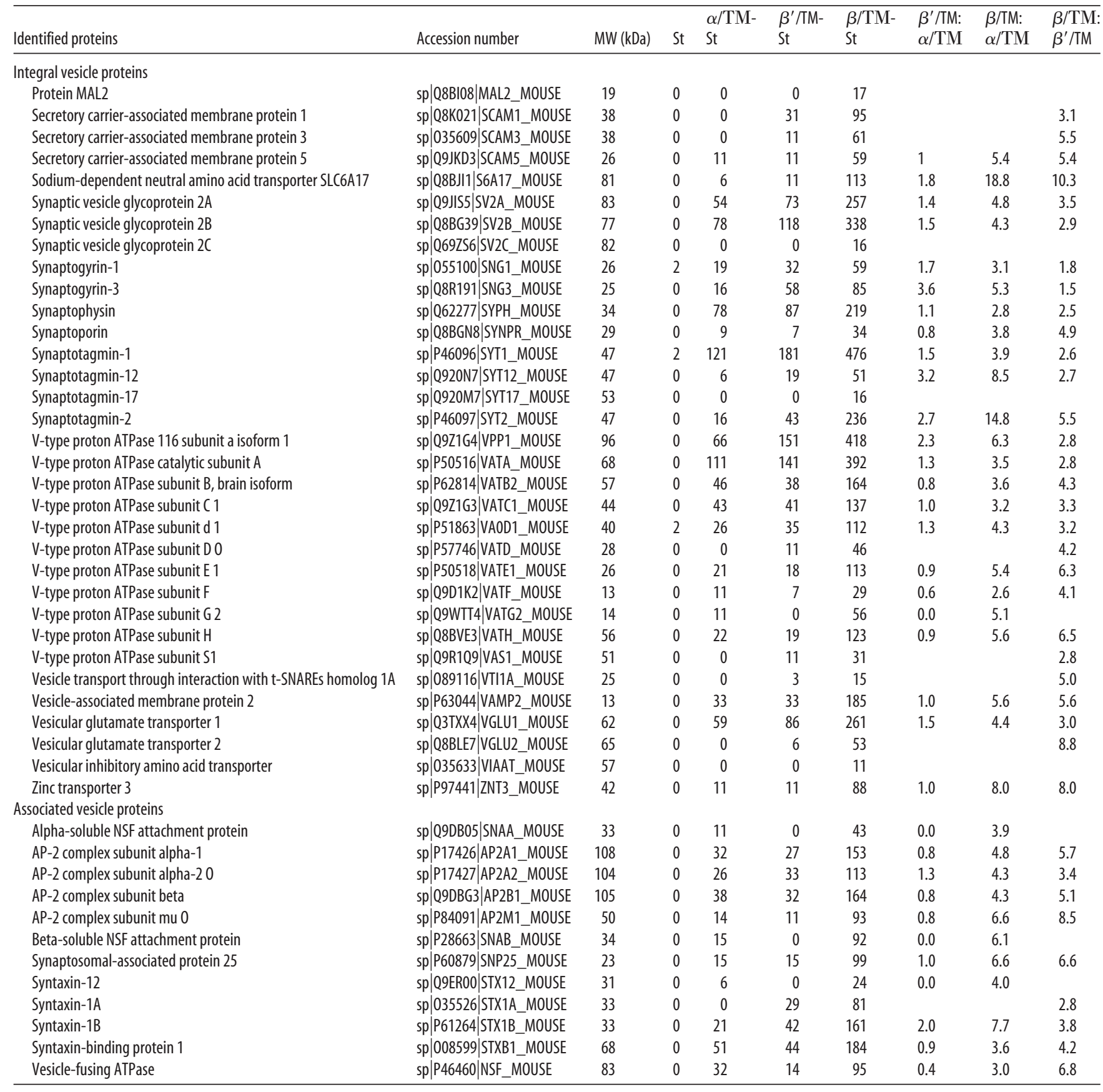

used the Y188 polyclonal antibody, which was raised against the C-terminal sequences of APP. As shown in Figure $2 C, D$, the positive immune-reactive signals are predominately associated with SV. This immunoreactivity is specific because secondary antibody alone gives no detectable signal (Fig. $2 B$ ). The EM result is consistent with our biochemical fractionation data (Fig. $2 A$ ): it is reasonable to assume that Y188 is detecting both full-length APP and CTF fragments localized in CA1 SV. In summary, the following evidence and published observations support the biological relevance of our proteomic data: (1) APP is found in SV (Figure 2B) (Groemer et al., 2011; Del Prete et al., 2014), APP and SV proteins are found in similar synaptosomal-derived fractions (Fig. 2A), and endogenous APP is present in fractions highly enriched in presynaptic termini (Groemer et al., 2011; Lundgren et al., 2015); (2) the evidence that binding to SV proteins is re- duced by N-terminal deletions of ISVAID (Fig. 1C; Tables 1, 2) and that ST peptide alone and ST-Ccas (Del Prete et al., 2014; Fanutza et al., 2015) do not bind SV-derived proteins suggests specificity; and (3) the in vivo interactome of the APP in brain reveals a protein network with SV proteins (Norstrom et al., 2010; Kohli et al., 2012).

Evidence that the ISVAID modifies the release of glutamatergic SV at SC-CA3 > CA1 pyramidal cell synapses Remarkably, the interactome of Ex/TM resembles that of the cytosolic domain of APP, specifically that of the JCasp region (Del Prete et al., 2014; Fanutza et al., 2015). Thus, APP may contain an ISVAID (Ex/TM) as well as a "cytosolic SV-interacting domain" (JCasp), suggesting a presynaptic role of APP in SV function. 
Table 2. List of integral SV proteins and proteins associated with SV that were included in the $\alpha / \mathrm{TM}, \boldsymbol{\beta} / \mathrm{TM}$ and Ex/TM-interactomes

\begin{tabular}{|c|c|c|c|c|c|c|c|c|c|}
\hline Identified proteins & Accession number & MW (kDa) & St & $\begin{array}{l}\alpha / \mathrm{TM}- \\
\text { St }\end{array}$ & $\begin{array}{l}\beta / \mathrm{TM}- \\
\text { St }\end{array}$ & $\begin{array}{l}\text { Ex/TM- } \\
\text { St }\end{array}$ & $\begin{array}{l}\beta / \mathrm{TM}: \\
\alpha / \mathrm{TM}\end{array}$ & Ex/TM: $\alpha / \mathrm{TM}$ & $\begin{array}{l}\text { Ex/TM: } \\
\beta / T M\end{array}$ \\
\hline \multicolumn{10}{|l|}{ Integral vesicle proteins } \\
\hline Protein MAL2 & sp|Q8BI08|MAL2_MOUSE & 19 & 0 & 0 & 6 & 8 & & & 1.3 \\
\hline Secretory carrier-associated membrane protein 1 & sp|Q8K021|SCAM1_MOUSE & 38 & 0 & 0 & 42 & 58 & & & 1.4 \\
\hline Secretory carrier-associated membrane protein 3 & sp|035609|SCAM3_MOUSE & 38 & 0 & 0 & 29 & 39 & & & 1.3 \\
\hline Secretory carrier-associated membrane protein 5 & sp|Q9JKD3|SCAM5_MOUSE & 26 & 0 & 0 & 31 & 34 & & & 1.1 \\
\hline Sodium-dependent neutral amino acid transporter SLC6A17 & sp|Q8BJI1|S6A17_MOUSE & 81 & 0 & 0 & 25 & 41 & & & 1.6 \\
\hline Synaptic vesicle glycoprotein $2 \mathrm{~A}$ & sp $\mid$ Q9JIS5|SV2A_MOUSE & 83 & 5 & 15 & 84 & 141 & 5.6 & 9.4 & 1.7 \\
\hline Synaptic vesicle glycoprotein 2B & sp|Q8BG39|SV2B_MOUSE & 77 & 13 & 0 & 158 & 211 & & & 1.3 \\
\hline Synaptic vesicle glycoprotein $2 C$ & sp|Q69ZS6|SV2C_MOUSE & 82 & 0 & 0 & 0 & 13 & & & \\
\hline Synaptogyrin-1 & sp|055100|SNG1_MOUSE & 26 & 0 & 6 & 39 & 58 & 6.5 & 9.666666667 & 1.5 \\
\hline Synaptogyrin-3 & sp|Q8R191|SNG3_MOUSE & 25 & 0 & 8 & 61 & 92 & 7.6 & 11.5 & 1.5 \\
\hline Synaptophysin & sp|Q62277|SYPH_MOUSE & 34 & 0 & 12 & 117 & 132 & 9.8 & 11.0 & 1.1 \\
\hline Synaptoporin & sp|Q8BGN8|SYNPR_MOUSE & 29 & 0 & 0 & 15 & 22 & & & 1.5 \\
\hline Synaptotagmin-1 & sp|P46096|SYT1_MOUSE & 47 & 0 & 0 & 212 & 324 & & & 1.5 \\
\hline Synaptotagmin-12 & sp|Q920N7|SYT12_MOUSE & 47 & 0 & 0 & 25 & 43 & & & 1.7 \\
\hline Synaptotagmin-17 & sp|Q920M7|SYT17_MOUSE & 53 & 0 & 0 & 13 & 22 & & & 1.7 \\
\hline Synaptotagmin-2 & sp|P46097|SYT2_MOUSE & 47 & 0 & 13 & 94 & 166 & 7.2 & 12.8 & 1.8 \\
\hline Synaptotagmin-5 & sp|Q9RON5|SYT5_MOUSE & 43 & 0 & 0 & 12 & 17 & & & 1.4 \\
\hline V-type proton ATPase 116 subunit a isoform 1 & sp|Q9Z1G4|VPP1_MOUSE & 96 & 6 & 24 & 198 & 247 & 8.3 & 10.3 & 1.2 \\
\hline V-type proton ATPase catalytic subunit A & sp|P50516|VATA_MOUSE & 68 & 8 & 32 & 136 & 232 & 4.3 & 7.3 & 1.7 \\
\hline V-type proton ATPase subunit B, brain isoform & sp|P62814|VATB2_MOUSE & 57 & 0 & 11 & 66 & 79 & 6.0 & 7.2 & 1.2 \\
\hline V-type proton ATPase subunit C 1 & sp|Q9Z1G3|VATC1_MOUSE & 44 & 0 & 14 & 49 & 61 & 3.5 & 4.4 & 1.2 \\
\hline V-type proton ATPase subunit d 1 & sp|P51863|VA0D1_MOUSE & 40 & 2 & 9 & 57 & 87 & 6.3 & 9.7 & 1.5 \\
\hline V-type proton ATPase subunit D 0 & sp|P57746|VATD_MOUSE & 28 & 0 & 9 & 28 & 31 & 3.1 & 3.4 & 1.1 \\
\hline V-type proton ATPase subunit E 1 & sp|P50518|VATE1_M0USE & 26 & 0 & 22 & 44 & 53 & 2.0 & 2.4 & 1.2 \\
\hline V-type proton ATPase subunit F & sp|Q9D1K2|VATF_MOUSE & 13 & 0 & 0 & 11 & 19 & & & 1.7 \\
\hline V-type proton ATPase subunit G 2 & sp|Q9WTT4|VATG2_MOUSE & 14 & 0 & 8 & 13 & 26 & 1.6 & 3.3 & 2.0 \\
\hline V-type proton ATPase subunit H & sp|Q8BVE3|VATH_MOUSE & 56 & 0 & 11 & 56 & 83 & 5.1 & 7.5 & 1.5 \\
\hline V-type proton ATPase subunit S1 & sp|Q9R1Q9|VAS1_MOUSE & 51 & 0 & 0 & 14 & 21 & & & 1.5 \\
\hline Vesicle transport through interaction with t-SNAREs homolog $1 \mathrm{~A}$ & sp|089116|VTI1A_MOUSE & 25 & 0 & 0 & 8 & 14 & & & 1.8 \\
\hline Vesicle-associated membrane protein 1 & sp|Q62442|VAMP1_MOUSE & 13 & 0 & 0 & 0 & 44 & & & \\
\hline Vesicle-associated membrane protein 2 & sp|P63044|VAMP2_MOUSE & 13 & 0 & 11 & 65 & 87 & 5.9 & 7.9 & 1.3 \\
\hline Vesicular glutamate transporter 1 & sp|Q3TXX4|VGLU1_MOUSE & 62 & 3 & 9 & 149 & 186 & 16.6 & 20.7 & 1.2 \\
\hline Vesicular glutamate transporter 2 & sp|Q8BLE7|VGLU2_MOUSE & 65 & 0 & 0 & 22 & 34 & & & 1.5 \\
\hline Vesicular inhibitory amino acid transporter & sp|035633|VIAAT_MOUSE & 57 & 0 & 7 & 0 & 9 & 0.0 & 1.3 & \\
\hline Zinc transporter 3 & sp|P97441|ZNT3_MOUSE & 42 & 0 & 0 & 19 & 28 & & & 1.5 \\
\hline \multicolumn{10}{|l|}{ Associated vesicle proteins } \\
\hline Alpha-soluble NSF attachment protein & sp|Q9DB05|SNAA_MOUSE & 33 & 0 & 13 & 11 & 24 & 0.8 & 1.8 & 2.2 \\
\hline AP-2 complex subunit alpha-1 & sp|P17426|AP2A1_MOUSE & 108 & 0 & 39 & 28 & 72 & 0.7 & 1.8 & 2.6 \\
\hline AP-2 complex subunit alpha-20 & sp|P17427|AP2A2_MOUSE & 104 & 0 & 31 & 24 & 64 & 0.8 & 2.1 & 2.7 \\
\hline AP-2 complex subunit beta & sp|Q9DBG3|AP2B1_MOUSE & 105 & 0 & 37 & 27 & 73 & 0.7 & 2.0 & 2.7 \\
\hline AP-2 complex subunit mu 0 & sp|P84091|AP2M1_MOUSE & 50 & 0 & 21 & 41 & 32 & 2.0 & 1.5 & 0.8 \\
\hline Beta-soluble NSF attachment protein & sp|P28663|SNAB_MOUSE & 34 & 0 & 23 & 31 & 34 & 1.3 & 1.5 & 1.1 \\
\hline Synaptosomal-associated protein 25 & sp|P60879|SNP25_MOUSE & 23 & 0 & 13 & 45 & 71 & 3.5 & 5.5 & 1.6 \\
\hline Syntaxin-12 & sp|Q9ER00|STX12_MOUSE & 31 & 0 & 0 & 9 & 21 & & & 2.3 \\
\hline Syntaxin-1A & sp|035526|STX1A_MOUSE & 33 & 0 & 0 & 25 & 39 & & & 1.6 \\
\hline Syntaxin-1B & sp|P61264|STX1B_M0USE & 33 & 0 & 12 & 45 & 73 & 3.8 & 6.1 & 1.6 \\
\hline Syntaxin-binding protein 1 & sp|008599|STXB1_MOUSE & 68 & 0 & 89 & 76 & 121 & 0.9 & 1.4 & 1.6 \\
\hline Vesicle-fusing ATPase & sp|P46460|NSF_MOUSE & 83 & 0 & 21 & 34 & 65 & 1.6 & 3.1 & 1.9 \\
\hline
\end{tabular}

The functional significance of SV-APP C-terminal interactions was investigated using the peptide JCasp linked to the cellpenetrating peptide Penetratin1 (Pen1) (Tamayev et al., 2012a). Pen1-JCasp, which is delivered inside neurons at hippocampal SC-CA3 $>$ CA1 synapses (Fanutza et al., 2015), reduced the release probability $(\mathrm{Pr})$ of glutamatergic SV. Pen1-JCasp had no effects in $A p p-\mathrm{KO}$ animals, indicating that it acts as a dominant negative inhibitor of a specific endogenous APP domain. In summary, Pen1-JCasp allowed us to study the function of the C-terminal APP domain in WT adult animals, eliminating the confounding effects associated with $A p p-\mathrm{KO}$ models, such as developmental issues and compensatory mechanisms mediated by APP-like Proteins-1 and -2 (Fanutza et al., 2015).
A similar approach could be used to study the functional relevance of the ISVAID since Ex/TM should act as a dominant negative inhibitor of the ISVAID's functions. JCasp was linked to Pen 1 because, to be biologically active, JCasp needs to access the neuronal synaptic cytosol (Fig. $3 A, B$ ) (Fanutza et al., 2015). In contrast, we postulate that Ex/TM may modulate SV biology by inhibiting intralumenal SV interactions, and that, as there is no known targeting signal to SV, Ex/TM applied extracellularly can enter the SV lumen during exocytosis and vesicular recycling (Fig. 3C). To test this hypothesis, we generated Ex/TM peptides with an N-terminal FITC label and incubated brain slices in FITC-Ex/TM. Uptake into cells was measured by intracellular localization of FITC-Ex/TM using confocal microscopy. After $3 \mathrm{~h}$ 
A

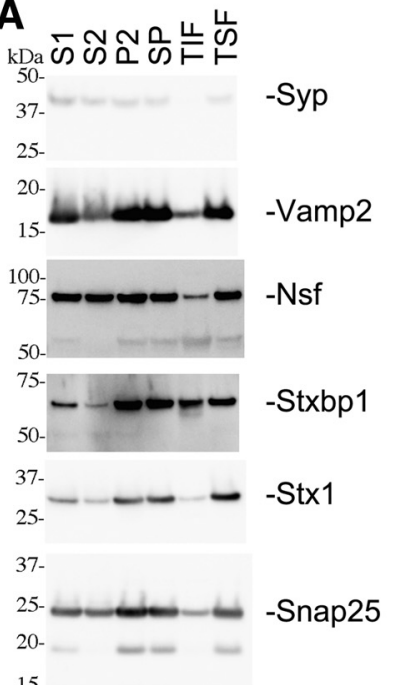

15

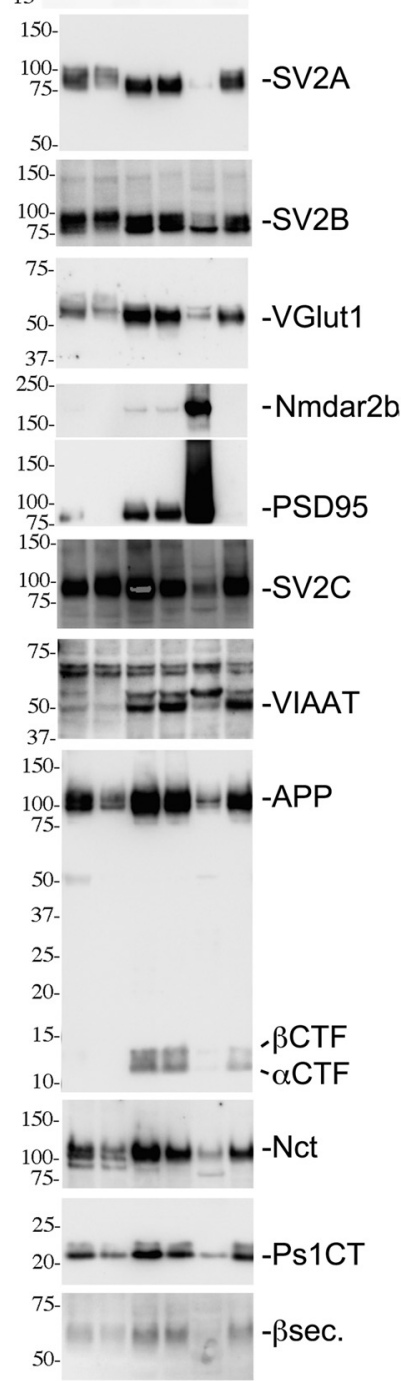

\section{B Control (without Y188)}

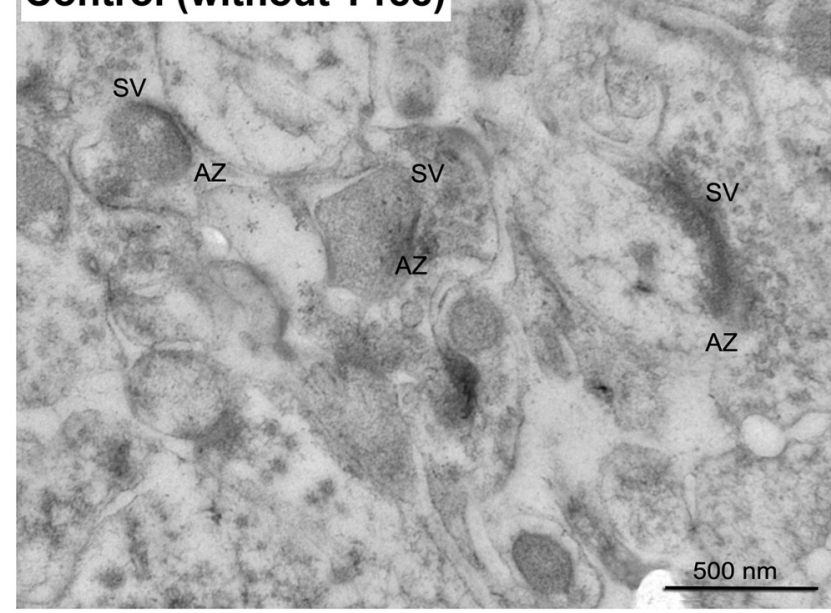

C

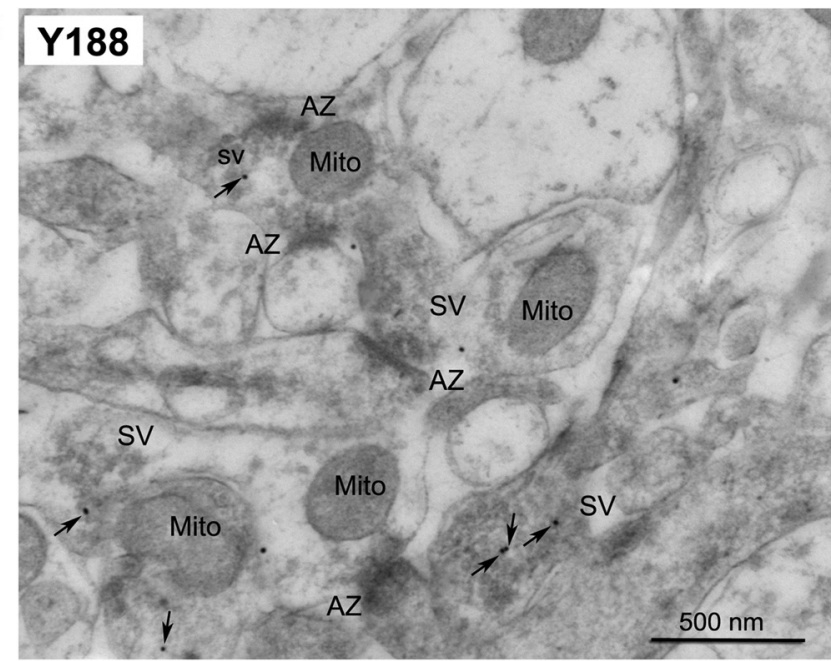

D

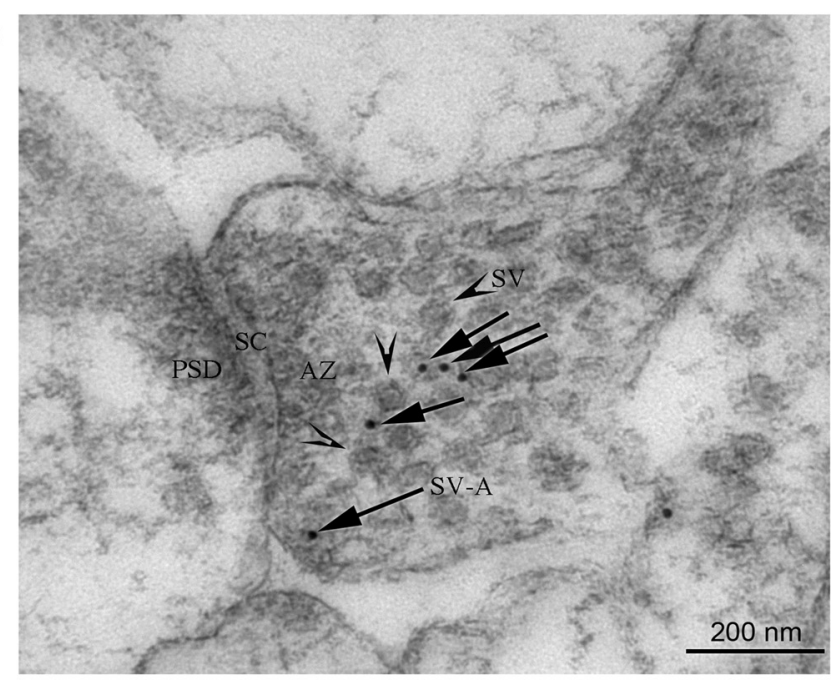

Figure 2. APP localizes at presynaptic vesicles. A, TIF and TSF were prepared from mouse cortex and analyzed by SDS-PAGE and Western analysis. Postnuclear supernatant is labeled S1. S2 fractions have been depleted of synaptic markers, present only in $\mathrm{P} 2$ and/or subsequent fractions. SPs contain both presynaptic and postsynaptic markers. The TIF is enriched in postsynaptic markers PSD95 and Nmdar2b, and the presynaptic markers Syp, Vamp2, Nsf, SNAP25, Stx1b, Stxbp1, SV2A, SV2B, SV2C, VGlut1, and VIAAT are enriched in the TSF. Fractions were analyzed for the presence of APP by blotting against the $C$ terminus, which recognizes full-length APP ( $\sim 100 \mathrm{kDa})$ and all C-terminal fragments $(\sim 10-15 \mathrm{kDa})$, for the $\mathrm{C}$ terminus of PS1, Nct, and $\beta$-secretase. Immuno-EM using secondary antibody alone (B) or an anti-APP-C-terminal antibody Y188 in mouse cerebral cortex (C) or hippocampal CA1 (D) shows that APP-positive signals are closely associated with presynaptic vesicles. We selected Y188 for I-EM because it has demonstrated specificity for APP in immunofluorescence experiments. Synapses were identified by morphology: SV (arrowheads), clefts (SC), the AZ, and the postsynaptic density (PSD). Larger arrows pointing to gold particles (10 nm) indicate distribution of APP predominately on SVs (SV-A in D). Mitochondria (Mito) are also indicated. Scale bars: $\boldsymbol{B}, \boldsymbol{C}, 500 \mathrm{~nm} ; \boldsymbol{D}, 200 \mathrm{~nm}$. 

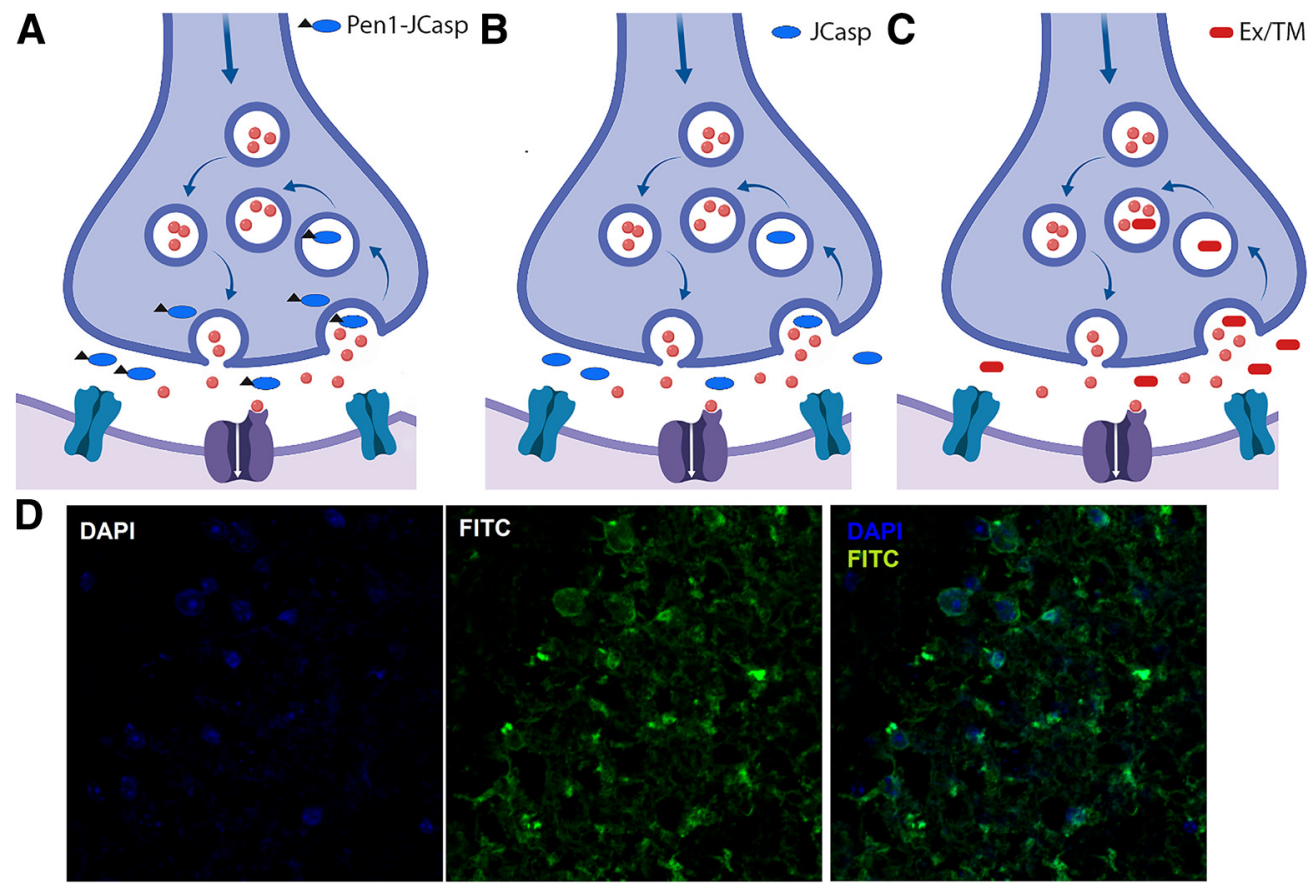

Figure 3. Ex/TM is uploaded into cells. Pen1-JCasp is present extracellularly, in SVs, and in the cytosol (A), whereas JCasp can only reside in extracellularly and in SVs $(\boldsymbol{B})$. The evidence that Pen1-JCasp, but not JCasp, reduces glutamate release (Fanutza et al., 2015) demonstrates that JCasp must be delivered to the cytosol to exert this biological activity. C, We postulate that Ex/TM is biologically active inside the SV and that Ex/TM can be uploaded in SV during SV recycling. D, Confocal microscopy analysis of FITC-Ex/TM in brain slices. Brain slices from 12-week-old mice were treated with $10 \mu \mathrm{m}$ FITC-Ex/TM in ACSF, fixed, and stained with DAPI. Hippocampi (CA1 shown here) were visualized by confocal microscopy. The images were merged in the right two panels. FITC-ExTM is taken up into cells.

incubation, internalization of FITC-Ex/TM is apparent (Fig. 3D). This experimental system does not rule out the possibility of Ex/TM acting at the cell surface, as there is abundant unincorporated peptide visible by microscopy, or acting at the endolysosomal pathway via endocytosis.

Synaptic transmission experiments were performed as follows: soon after preparation, the brain slices were incubated in $200 \mathrm{ml}$ of ACSF containing the indicated concentrations of Ex/ TM. Recordings were performed between $\sim 1$ and $4 \mathrm{~h}$ after preparation of slices and incubation with the peptide. To test whether Ex/TM (Fig. 4A) caused presynaptic impairments acting via dominant negative inhibition of APP, we estimated its effects on the release of glutamatergic SV in both WT and App-KO mice. First, we analyzed a form of short-term synaptic plasticity, paired-pulse facilitation (PPF). PPF is determined, at least in part, by changes in $\mathrm{P} r$, such that a decrease in $\mathrm{Pr}$ leads to an increase in facilitation and vice versa (Zucker and Regehr, 2002). In addition, we analyzed mEPSCs. The frequency of mEPSC is also in part determined by changes in $\mathrm{P} r$, such that a decrease in $\mathrm{Pr}$ leads to a decrease in frequency and vice versa. Ex/TM significantly decreased PPF measured at both $50 \mathrm{~ms}$ interstimulus interval (ISI) [ordinary one-way ANOVA summary: $F=20.46, p<$ 0.0001 (significant): post hoc Tukey's multiple-comparisons test: $\mathrm{WT}$ vs $A p p-\mathrm{KO}, p=0.9994$ (not significant); WT vs $\mathrm{WT}+\mathrm{Ex} /$ TM, $p<0.0001$ (significant); WT vs $A p p-\mathrm{KO}+\mathrm{Ex} / \mathrm{TM}, p=$ 0.8795 (not significant); $A p p-\mathrm{KO}$ vs WT+Ex/TM, $p<0.0001$ (significant); $A p p-\mathrm{KO}$ vs $A p p-\mathrm{KO}+\mathrm{Ex} / \mathrm{TM}, p=0.9398$ (not significant); $\mathrm{WT}+\mathrm{Ex} / \mathrm{TM}$ vs App-KO+Ex/TM, $p<0.0001$ (significant)] and $200 \mathrm{~ms}$ ISI [ordinary one-way ANOVA summary: $F=13.42, p<0.0001$ (significant): post hoc Tukey's multiplecomparisons test: WT vs $A p p-\mathrm{KO}, p=0.9994$ (not significant); WT vs WT+Ex/TM, $p<0.0001$ (significant); WT vs $A p p-$ $\mathrm{KO}+\mathrm{Ex} / \mathrm{TM}, p=0.8795$ (not significant); App-KO vs WT $+\mathrm{Ex} /$
$\mathrm{TM}, p<0.0001$ (significant); $A p p-\mathrm{KO}$ vs $A p p-\mathrm{KO}+\mathrm{Ex} / \mathrm{TM}, p=$ 0.9398 (not significant); $\mathrm{WT}+\mathrm{Ex} / \mathrm{TM}$ vs $A p p-\mathrm{KO}+\mathrm{Ex} / \mathrm{TM}, p=$ 0.0004 (significant)] in WT but not App-KO animals (Fig. 4B). Moreover, Ex/TM significantly increased the frequency of mEPSC [ANOVA summary: $F=41.25, p<0.0001$ (significant); post hoc Tukey's multiple-comparisons test: WT vs $A p p-\mathrm{KO}, p=$ 0.9950 (not significant); WT vs WT $+\mathrm{Ex} / \mathrm{TM}, p<0.0001$ (significant); WT vs $A p p-\mathrm{KO}+\mathrm{Ex} / \mathrm{TM}, p=0.7305$ (not significant); $A p p-\mathrm{KO}$ vs WT+Ex/TM, $p<0.0001$ (significant); $A p p-\mathrm{KO}$ vs $A p p-\mathrm{KO}+\mathrm{Ex} / \mathrm{TM}, p=0.8636$ (not significant); WT+Ex/TM vs $A p p-\mathrm{KO}+\mathrm{Ex} / \mathrm{TM}, p<0.0001$ (significant)] (Fig. 3C), but had no effect on mEPSC amplitude [ANOVA summary: $F=1.689$, $p=0.1866$ (not significant)] or decay time [ANOVA summary: $F=1.862, p=0.1535$ (not significant)] (Fig. 4C), in WT but not App-KO animals. Together, these data suggest that Ex/TM increases glutamate release at SC-CA3 $>$ CA1 pyramidal cell synapses via a presynaptic mechanism of action, possibly by increasing the Pr of excitatory SV. The evidence that Ex/TM does not alter the frequency of mEPSCs and PPF in App-KO animals could have two explanations: (1) Ex/TM acts as a dominant negative inhibitor of endogenous APP; or (2) APP could function as a receptor for Ex/TM, implying direct binding of Ex/TM to APP. If Ex/TM were a ligand of APP, we would have expected to detect a large amount of APP peptides in the Ex/TM-St pull downs. Indeed, APP should have been the most abundant protein isolated in these pull-downs. However, our proteomic experiments were inconsistent with the possibility, as Ex/TM-St pulled-down few murine APP peptides, which could derive from APP molecules contained in SV. Thus, the straightforward interpretation of these data is that Ex/TM acts as a dominant negative inhibitor of endogenous APP. It is worth noting that, while both Pen1-JCasp and Ex/TM modulate glutamatergic SV release, they trigger opposite effects: 
A

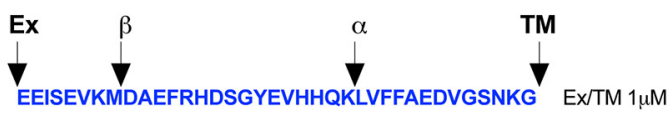

B

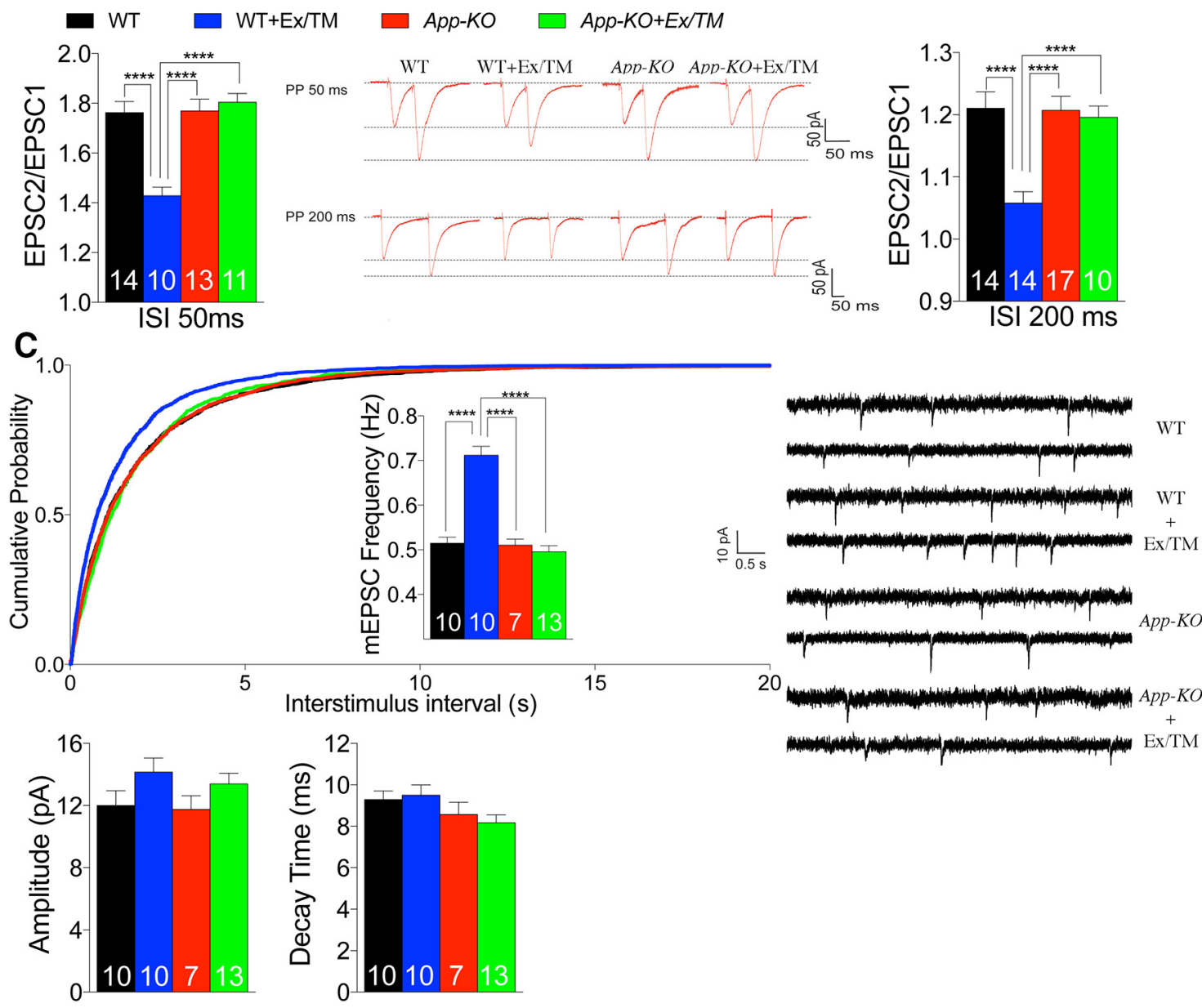

Figure 4. Ex/TM increases glutamate release: APP is required for this effect. $A$, Sequence of the Ex/TM peptide. Ex indicates the arbitrarily chosen $\mathrm{NH}_{2}$ terminus for our analysis; $\beta$ and $\alpha$ indicate the sites cleaved by $\beta$ - and $\alpha$-secretase, respectively; and TM indicates the beginning of the transmembrane region of APP. B, Average PPF (second EPSP/first EPSP) at 50 and $200 \mathrm{~ms}$ ISI. Representative traces of EPSPs are shown. Ex/TM significantly decreases PPF in WT, but not App-KO, rats. C, Cumulative probability of AMPAR-mediated mEPSC interevent intervals. Inset in cumulative probability graphs represents average mEPSC frequency. mEPSC frequency was significantly increased by Ex/TM in WT, but not App-KO, mice. Amplitudes and decay time of mEPSCs were not changed by Ex/TM. Representative recording traces of mEPSCs are shown. Data were analyzed by ordinary one-way ANOVA followed by post hoc Tukey's multiple-comparisons test when ANOVA showed statistically significant differences. The number of recordings analyzed for each group are indicated inside the bars. Data are mean \pm SEM. ${ }^{* * * *} p<0.0001$.

Ex/TM facilitates, whereas Pen1-JCasp hampers, the release of excitatory SV.

Evidence that $\beta$ and $\alpha$ cleavage of the ISVAID may promote glutamate release

The acidic $\mathrm{pH}$ of SVs favors $\beta$ cleavage, and indeed there is an enrichment of $\beta$-secretase and $\beta$ cleavage APP metabolites in SV subcellular fractionations (Del Prete et al., 2014) (Fig. 2A). Thus, it is reasonable to hypothesize that processing of APP by $\beta$-secretase may cut inside the ISVAID of APP (Fig. 1; Tables 1, 2 ), destabilizing these interactions, thereby modulating the presynaptic function of APP. As an initial test of this hypothesis, we compared the effects of the Ex/TM and $\beta /$ TM peptides (Fig. $5 A$ ). If $\beta$ cleavage of APP destabilizes the intraluminal SV-APP interactions, $\beta /$ TM should not alter glutamate release. Ex/TM reproducibly reduced PPF and increased mEPSC frequency in a dose-dependent manner (Fig. $5 B, C$ ), without affecting mEPSC amplitude or decay time (Fig. 5C). We also measured the AMPA/ NMDA ratio, which is modified by qualitative and/or quantitative alterations in either AMPAR or NMDAR at the postsynaptic termini and found no effects of Ex/TM (Fig. 5D), confirming that this peptide modifies glutamatergic transmission predominantly via a presynaptic mechanism of action. Conversely, treatment of brain slices with $1 \mu \mathrm{M}$ concentration of the $\beta / \mathrm{TM}$ peptide did not alter glutamatergic synaptic transmission (Fig. 5). Together, these data are consistent with the hypothesis that $\beta$ and $\alpha$ processing of APP splits the ISVAID and may facilitate glutamate release.

To further define the Ex/TM regions that interfere with glutamate release, we tested two more peptides: $\mathrm{Ex} / \beta$, which spans from the Ex site to the $\beta$ cleavage site; and $\mathrm{Ex} / \alpha$, which extends from the Ex site to the $\alpha$ cleavage site (Fig. 5A). While $\mathrm{Ex} / \beta$ did not change glutamatergic transmission (Fig. 5), $1 \mu \mathrm{M}$ concentration of Ex/ $\alpha$ reduced PPF at $50 \mathrm{~ms}$ ISI (Fig. $5 B$ ) and increased 

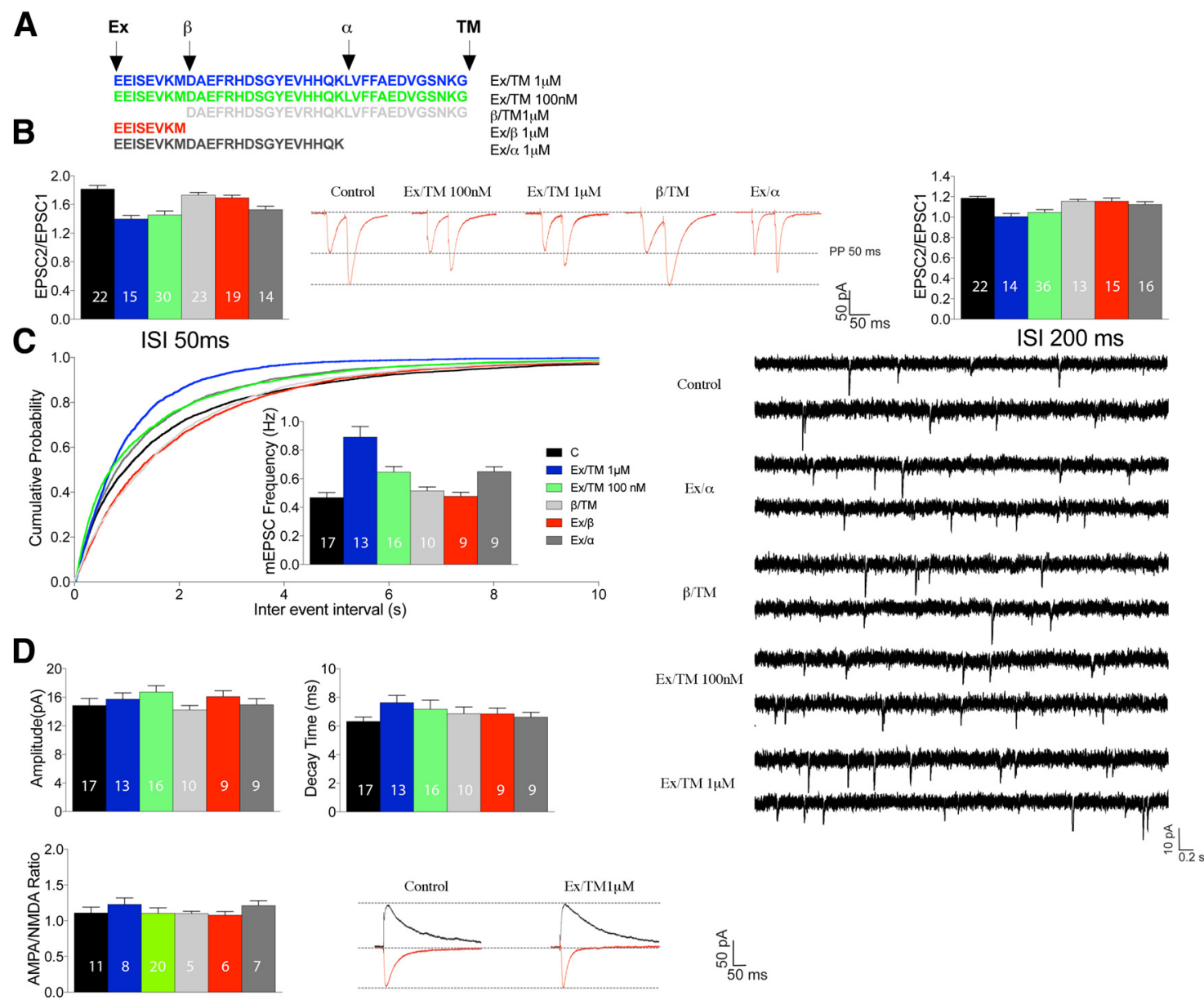

Figure 5. The regions of Ex/TM NH 2 - and $\mathrm{COOH}$-terminal to the $\beta$ cleavage site are required to increase glutamate release. $A$, Sequence of Ex/TM, $\beta / \mathrm{TM}, \mathrm{Ex} / \beta$, and Ex/ $\alpha$. $\boldsymbol{B}$, Average PPF at 50 and $200 \mathrm{~ms} \mathrm{ISI}$ and representative traces of EPSPs evoked at $50 \mathrm{~ms} \mathrm{ISI}$ are shown. Ex/TM and Ex/ $\alpha$ decrease PPF. C, Ex/TM and Ex/ $\alpha$ increase mEPSC frequency. Amplitudes and decay time were not changed. Representative recording traces of mEPSCs are shown. D, AMPA/NMDA ratio was not changed by any peptide. Data were analyzed by ordinary one-way ANOVA followed by post hoc Tukey's multiple-comparisons test when ANOVA showed statistically significant differences. The number of recordings analyzed for each group are indicated inside the bars. Data are mean \pm SEM.

I/O curve

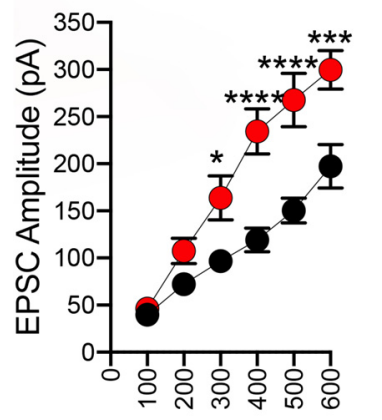

Stimulation Intensity $(\mu \mathrm{A})$

Figure 6. Ex/TM increases synaptic strength. Input- output relationships for AMPA receptor-mediated EPSCs in vehicle $(n=6)$ and Ex/TM $(n=6)$ group. Traces showing averages of 15 sweeps of AMPA receptor-mediated EPSCs at each stimulation intensity. Data were analyzed by two-way repeated-measures ANOVA followed by post hoc Tukey's multiple-comparisons test. The number of recordings analyzed for each group are indicated inside the bars. Data are mean \pm SEM. ${ }^{*} p<0.05,{ }^{* * *} p<0.001,{ }^{* * * *} p<$ 0.0001 .

mEPSC frequency (Fig. 5C), similarly to the $100 \mathrm{~nm}$ concentration of Ex/TM. The data obtained with these peptides were analyzed together by ordinary one-way ANOVA. The statistical analyses gave the following results: (1) ANOVA summary of PPF at $50 \mathrm{~ms}$ ISI (Fig. $5 B$ ): $F=13.82, p<0.0001$ (significant): post hoc
Tukey's multiple-comparisons test: $\mathrm{C}$ vs $\mathrm{Ex} / \beta, p=0.4564 ; \mathrm{C}$ vs $\beta / \mathrm{TM}, p=0.6487$; $\mathrm{C}$ vs $\mathrm{Ex} / \alpha, p<0.0001$ (significant); $\mathrm{C}$ vs Ex/TM-1 $\mu \mathrm{M}, p<0.0001$ (significant); C vs Ex/TM $100 \mathrm{nM}, p<0.0001$ (significant); $\mathrm{Ex} / \beta$ vs $\beta / \mathrm{TM}, p=0.9925 ; \mathrm{Ex} / \beta$ vs $\mathrm{Ex} / \alpha, p=0.1377 ; \mathrm{Ex} / \beta$ vs $\mathrm{Ex} / \mathrm{TM} 1 \mu \mathrm{M}$, $p=0.0006$ (significant); $\mathrm{Ex} / \beta$ vs $\mathrm{Ex} / \mathrm{TM}$ $100 \mathrm{nM}, p=0.0217$ (significant); $\beta / \mathrm{TM}$ vs $\mathrm{Ex} / \alpha, p=0.0055$ (significant); $\beta / \mathrm{TM}$ vs $\mathrm{Ex} / \mathrm{TM}-1 \mu \mathrm{M}, p<0.0001$ (significant); $\beta / \mathrm{TM}$ vs Ex/TM-100 nM, $p=0.0007$ (significant); $\mathrm{Ex} / \alpha$ vs $\mathrm{Ex} / \mathrm{TM}-1 \mu \mathrm{M}, p=$ 0.3142; $\mathrm{Ex} / \alpha$ vs $\mathrm{Ex} / \mathrm{TM}-100 \mathrm{nM}, p=$ 0.8919; Ex/TM-1 $\mu \mathrm{M}$ vs Ex/TM-100 nM, $p=9696$; (2) ANOVA summary of PPF at 200 ms ISI (Fig. $5 B$ ): $F=13.82, p<0.0001$ (significant): post hoc Tukey's multiplecomparisons test: $\mathrm{C} v \mathrm{Ex} / \beta, p=0.9513$; $\mathrm{C}$ vs $\beta / \mathrm{TM}, p=0.8793 ; \mathrm{C}$ vs $\mathrm{Ex} / \alpha, p=$ 0.4791; C vs Ex/TM-1 $\mu \mathrm{M}, p<0.0001$ (significant); C vs Ex/TM-100 nM, $p=0.0007$ (significant); $\mathrm{Ex} / \beta$ vs $\beta / \mathrm{TM}, p>0.9999 ; \mathrm{Ex} / \beta$ vs $\mathrm{Ex} / \alpha, p=0.9585 ; \mathrm{Ex} / \beta$ vs $\mathrm{Ex} / \mathrm{TM}-1$ $\mu \mathrm{M}, p=0.0011$ (significant); $\mathrm{Ex} / \beta$ vs $\mathrm{Ex} / \mathrm{TM}-100 \mathrm{nM}, p=0.0386$ (significant); $\beta / \mathrm{TM}$ vs $\mathrm{Ex} / \alpha, p=0.9142 ; \beta / \mathrm{TM}$ vs Ex/TM-1 $\mu \mathrm{M}$, 
Table 3. APP-derived bait pull-downs contained large amounts of VGlut1, VGlut2, Mal2, and SV2b peptides, but very few peptides derived from VIAAT and SV2c

\begin{tabular}{|c|c|c|c|c|c|c|}
\hline Identified proteins & Accession number & $\mathrm{MW}(\mathrm{kDa})$ & ST & $\alpha / \mathrm{TM}-\mathrm{St}$ & $\beta^{\prime} / \mathrm{TM}-\mathrm{St}$ & $\beta / \mathrm{TM}-\mathrm{St}$ \\
\hline \multicolumn{7}{|l|}{ Experiment 1} \\
\hline Vesicular glutamate transporter 1 & sp|Q3TXX4|VGLU1_MOUSE & 62 & 0 & 59 & 86 & 261 \\
\hline Vesicular glutamate transporter 2 & sp|Q8BLE7|VGLU2_MOUSE & 65 & 0 & 0 & 6 & 53 \\
\hline Synaptic vesicle glycoprotein $2 B$ & sp|08BG39|SV2B_MOUSE & 77 & 0 & 78 & 118 & 338 \\
\hline Protein MAL2 & sp|Q8BI08|MAL2_MOUSE & 19 & 0 & 0 & 0 & 17 \\
\hline Vesicular inhibitory amino acid transporter & sp|035633|VIAAT_MOUSE & 57 & 0 & 0 & 0 & 11 \\
\hline Synaptic vesicle glycoprotein $2 C$ & sp|Q69ZS6|SV2C_MOUSE & 82 & 0 & 0 & 0 & 16 \\
\hline Experiment 2 & & & & $\alpha / \mathrm{TM}-\mathrm{St}$ & $\beta / \mathrm{TM}-\mathrm{St}$ & Ex/TM-St \\
\hline Vesicular glutamate transporter 1 & sp|Q3TXX4|VGLU1_MOUSE & 62 & 3 & 9 & 149 & 186 \\
\hline Vesicular glutamate transporter 2 & sp|Q8BLE7|VGLU2_MOUSE & 65 & 0 & 0 & 22 & 34 \\
\hline Synaptic vesicle glycoprotein 2B & sp|Q8BG39|SV2B_MOUSE & 77 & 13 & 0 & 158 & 211 \\
\hline Protein MAL2 & sp|Q8BI08|MAL2_MOUSE & 19 & 0 & 0 & 6 & 8 \\
\hline Vesicular inhibitory amino acid transporter & sp|035633|VIAAT_MOUSE & 57 & 0 & 7 & 0 & 9 \\
\hline Synaptic vesicle glycoprotein $2 C$ & sp|069ZS6|SV2C_MOUSE & 82 & 0 & 0 & 0 & 13 \\
\hline Experiment 3 & & & & ST-AID & & \\
\hline Vesicular glutamate transporter 1 & sp|Q3TXX4|VGLU1_MOUSE & 62 & 0 & 109 & & \\
\hline Vesicular glutamate transporter 2 & sp|Q8BLE7|VGLU2_MOUSE & 65 & 0 & 17 & & \\
\hline Synaptic vesicle glycoprotein $2 B$ & sp|Q8BG39|SV2B_MOUUSE & 77 & 0 & 131 & & \\
\hline Protein MAL2 & sp|Q8BI08|MAL2_MOUSE & 19 & 0 & 8 & & \\
\hline Vesicular inhibitory amino acid transporter & sp|035633|VIAAT_MOUSE & 57 & 0 & 0 & & \\
\hline Synaptic vesicle glycoprotein $2 C$ & sp|069ZS6|SV2C_MOUSE & 82 & 0 & 5 & & \\
\hline Experiment 4 & & & & ST-AID & ST-Cas & ST-JCasp \\
\hline Vesicular glutamate transporter 1 & sp|Q3TXX4|VGLU1_MOUSE & 62 & 0 & 46 & 6 & 44 \\
\hline Vesicular glutamate transporter 2 & sp|Q8BLE7|VGLU2_MOUSE & 65 & 0 & 0 & 0 & 5 \\
\hline Synaptic vesicle glycoprotein 2B & sp|Q8BG39|SV2B_MOUSE & 77 & 0 & 59 & 6 & 71 \\
\hline Protein MAL2 & sp|Q8BI08|MAL2_MOUSE & 19 & 0 & 5 & 0 & 12 \\
\hline Vesicular inhibitory amino acid transporter & sp|035633|VIAAT_MOUSE & 57 & 0 & 0 & 0 & 2 \\
\hline Synaptic vesicle glycoprotein $2 C$ & sp|069ZS6|SV2C_MOUSE & 82 & 0 & 0 & 0 & 0 \\
\hline
\end{tabular}

$p<0.0001$ (significant); $\beta / \mathrm{TM}$ vs Ex/TM-100 nM, $p=0.0057$ (significant); Ex/ $\alpha$ vs Ex/TM-1 $\mu \mathrm{M}, p=0.0233$ (significant); $\mathrm{Ex} / \alpha$ vs $\mathrm{Ex} / \mathrm{TM}-100 \mathrm{nM}, p=0.3049 ; \mathrm{Ex} / \mathrm{TM}-1 \mu \mathrm{M}$ vs Ex/TM-100 nM, $p=8655$; (3) ANOVA summary of mEPSC frequency (Fig. $5 C$ ): $F=15.09, p<0.0001$ (significant); post hoc Tukey's multiplecomparisons test: $\mathrm{C}$ vs $\mathrm{Ex} / \beta, p>0.9999 ; \mathrm{C}$ vs $\beta / \mathrm{TM}, p=0.9078$; $\mathrm{C} v \mathrm{Ex} / \alpha, p=0.0111$ (significant); $\mathrm{C}$ vs Ex/TM-1 $\mu \mathrm{M}, p<0.0001$ (significant); C vs Ex/TM-100 nM, $p=0.0193$ (significant); $\mathrm{Ex} / \beta$ vs $\beta / \mathrm{TM}, p=0.9713 ; \mathrm{Ex} / \beta$ vs $\mathrm{Ex} / \alpha, p=0.0296$ (significant); $\mathrm{Ex} / \beta$ vs Ex/TM-1 $\mu \mathrm{M}, p<0.0001$ (significant); $\mathrm{Ex} / \beta$ vs Ex/TM-100 nM, $p=0.0460$ (significant); $\beta / \mathrm{TM}$ vs $\mathrm{Ex} / \alpha, p=0.1244 ; \beta / \mathrm{TM}$ vs $\mathrm{Ex} / \mathrm{TM}-1 \mu \mathrm{M}, p<0.0001$ (significant); $\beta / \mathrm{TM}$ vs Ex/TM-100 nM, $p=0.1735 ; \mathrm{Ex} / \alpha$ vs $\mathrm{Ex} / \mathrm{TM}-1 \mu \mathrm{M}, p=0.0023$ (significant); $\mathrm{Ex} / \alpha$ vs Ex/TM-100 nM, $p>0.9999$; Ex/TM $1 \mu \mathrm{M}$ vs Ex/TM-100 nM, $p=0.0026$ (significant); (4) ANOVA summary of mEPSC amplitude (Fig. $5 C$ ): $F=1.15, p=0.3427$; (5) ANOVA summary of mEPSC decay time (Fig. $5 C$ ): $F=1.046, p=0.3980$; and (6) ANOVA summary of AMPA/NMDA ratio (Fig. $5 D$ ): $F=0.8506$, $p=0.5199$.

Finally, we analyzed AMPA receptor-mediated EPSCs evoked by various stimulus intensities. The input-output relationship of AMPA receptor-mediated EPSCs of Ex/TM group displayed significant increases in the amplitudes of evoked EPSCs compared with vehicle controls; statistical assessment by two-way repeatedmeasures ANOVA shows a significant effect of row factor $\left(F_{(5,60)}=40.03 ; p<0.0001\right)$, column factor $\left(F_{(1,60)}=55.96 ; p<\right.$ $0.0001)$, and row-column interaction $\left(F_{(5,60)}=3.590 ; p=\right.$ 0.0066); post hoc Tukey's multiple-comparisons test shows that ISVAID significantly increases basal synaptic transmission compared with vehicle control (Fig. 6), suggesting that Ex/TM promotes basal synaptic transmission.

\section{APP tunes the release of excitatory but not inhibitory SV}

GABAergic inhibitory interneurons constitute only $\sim 10 \%$ of hippocampal neurons but are important for the regulation of the hippocampal network (Freund and Buzsáki, 1996; Chamberland and Topolnik, 2012). A proteomic comparison of glutamatergic (VGlut1-positive) and GABAergic (VIAAT-positive) SVs showed that the excitatory and inhibitory SVs share a qualitatively and quantitatively similar composition, with very few proteins segregating to one type of SV. These include the neurotransmitter transporter (VGlut1 and VGlut2 in excitatory SV, VIAAT in inhibitory SV), SV2b and Mal2 that are specifically present in excitatory SV, and SV2c, which is almost exclusively present in inhibitory SV (Grønborg et al., 2010). Remarkably, Ex/TM-St pull-downs contained large amounts of VGlut1, VGlut2, Mal2, and SV2b peptides, but very few peptides derived from VIAAT and SV2c (Table 3). Analysis of pull-downs previously performed with baits containing APP-cytosolic domain sequences (St-AID, which contains the entire APP intracellular domain, St-JCasp, which contain the $\mathrm{NH}_{2}$-terminal soluble cytosolic peptides derived from caspase cleavage of AID) revealed a similar binding pattern: VGlut1, VGlut2, Mal2, and SV2b abundantly bind StAID and St-JCasp, whereas VIAAT and SV2c do not (Table 3). The simplest explanation for these data is that Ex/TM-St, St-AID, and St-JCasp bind directly to proteins that are specifically present in excitatory SVs (i.e., VGlut1/2, SV2b, and Mal2). This possibility is currently under investigation. Regardless, if these observations have biological significance, Ex/TM should not alter GABA release. To test this prediction and to test whether this APP function can be replicated in a different species, we compared the effects of Ex/TM on glutamate and GABA release in rats' acute hippocampal slices. As observed in murine SC-CA3 $>$ CA1 pyramidal cell synapses (Fig. 5), Ex/TM increased mEPSC frequency 
A
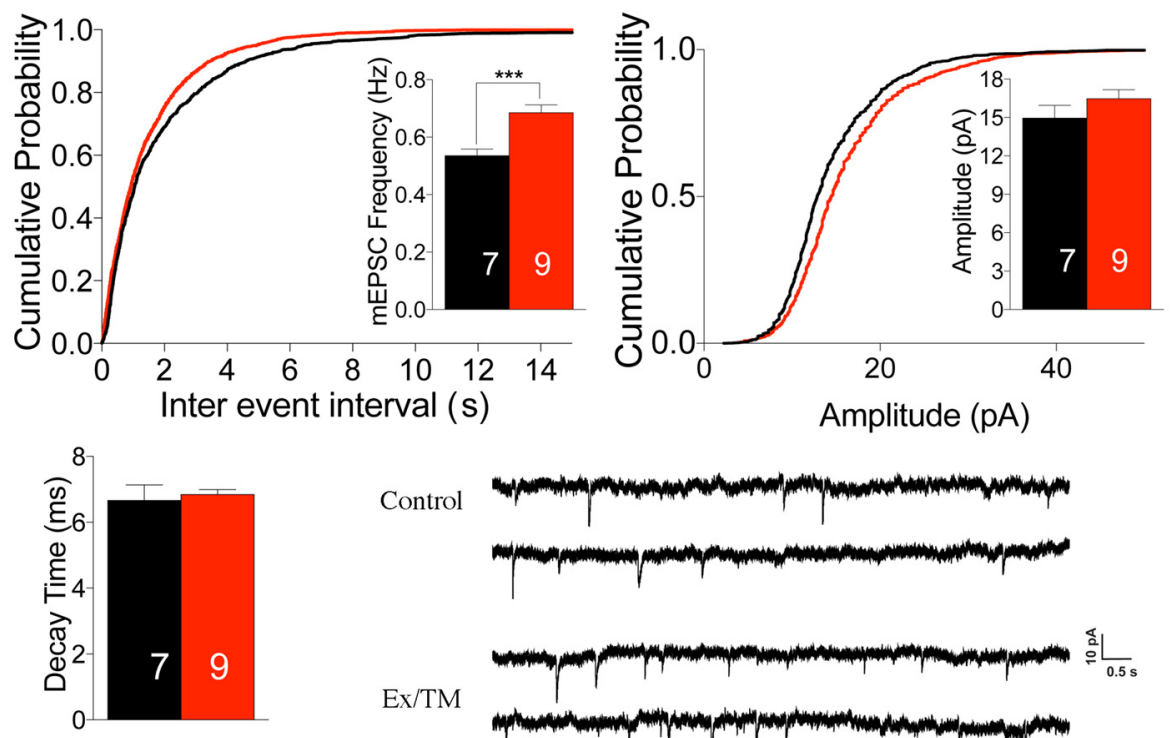

Control

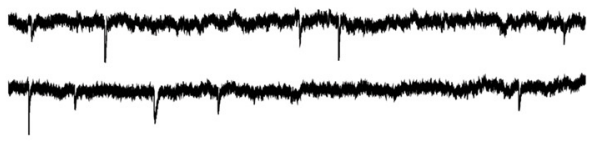

$\mathrm{Ex} / \mathrm{TM}$

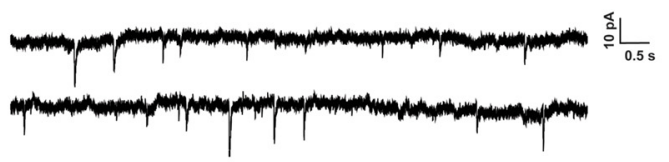

B
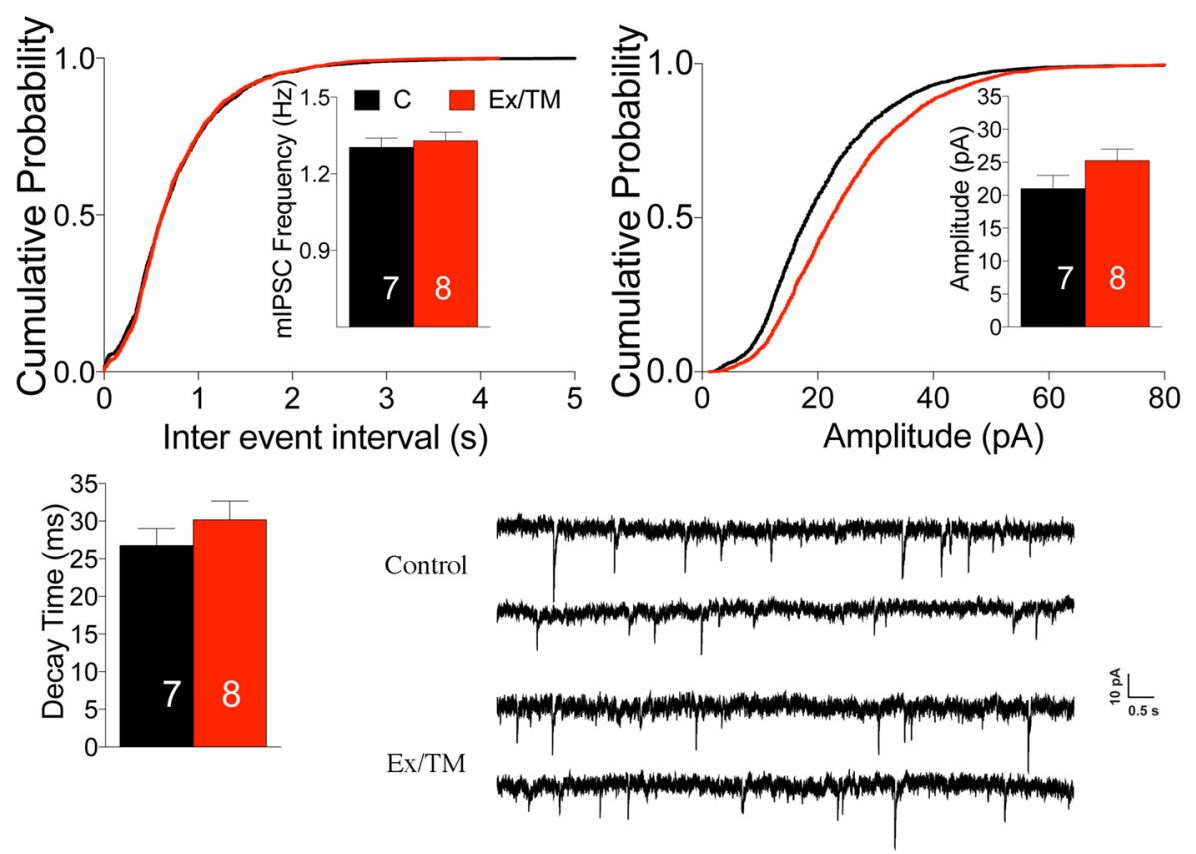

Figure 7. Ex/TM does not alter GABA transmission at inhibitory CA1 synapses. $A$, Ex/TM increases mEPSC frequency, but not amplitude and decay time. Representative recording traces of $m E$ EPSCS are shown. $\boldsymbol{B}$, Ex/TM does not alter frequency, amplitude, or decay time of mIPSCs. Representative recording traces of mIPSCs are shown. Data were analyzed by unpaired $t$ test. The number of recordings analyzed for each group are indicated inside the bars. Data are mean \pm SEM. ${ }^{* * *} p<0.001$.

Table 4. Abbreviations ${ }^{a}$

\begin{tabular}{ll}
\hline Abbreviation & Term \\
\hline ISVAID & Intraluminal SV-APP interacting domain of APP \\
JCasp & Intracytosolic APP domain that terminates (C-terminus) at Asp664, where caspases cleave APP; caspases cleave APP between Asp664 and Ala665 \\
Ccas & Intracytosolic APP domain that initiates (N-terminus) at Ala665 \\
Ex/TM & Intraluminal/extracellular APP fragment with N-terminus at Glu589 and C-terminus at Gly622; this sequence contains the ISVAID domain \\
$\beta / T M$ & Intraluminal/extracellular APP fragment with N-terminus at Asp597 ( $\beta$-cleavage site) and C-terminus at Gly622 \\
$\beta^{\prime} / T M$ & Intraluminal/extracellular APP fragment with N-terminus at Glu607 ( $\beta^{\prime}$-cleavage site) and C-terminus at Gly622 \\
$\alpha / T M$ & Intraluminal/extracellular APP fragment with N-terminus at Leu613 ( $\alpha$-cleavage site) and C-terminus at Gly622 \\
$\beta C T F$ & Membrane-bound C-terminal fragment of APP produced by $\beta$-secretase \\
$\alpha$ CTF & Membrane-bound C-terminal fragment of APP produced by $\alpha$-secretase \\
SAPP $\beta$ & Soluble N-terminal fragment of APP produced by $\beta$-secretase \\
SAPP $\alpha$ & Soluble N-terminal fragment of APP produced by $\alpha$-secretase \\
ST & Strep-tag peptide-WSHPQFEK \\
\hline${ }_{0}$ Th &
\end{tabular}

${ }^{a}$ The numbering of APP refers to the isoform of 695 , which is the main CNS form for APP. 
(unpaired $t$ test, $p=0.0010$ ), without affecting mEPSC amplitude (unpaired $t$ test, $p=0.207$ ) or decay time (unpaired $t$ test, $p=0.6879$ ) (Fig. $7 A$ ) also in rat SC-CA3 $>$ CA1 pyramidal cell synapses. In contrast, when mIPSCs where analyzed, Ex/TM showed no significant effect on frequency (unpaired $t$ test, $p=$ 0.593 ), amplitude (unpaired $t$ test, $p=0.1263$ ), or decay time (unpaired $t$ test, $p=0.3226$ ) of mIPSCs (Fig. 7B). Table 4 lists abbreviations used herein.

\section{Discussion}

Using an unbiased proteomic methodology, we found that: (1) the intraluminal region of APP juxtaposed to the vesicular membrane contains a putative interaction domain, herein called ISVAID, which establishes an intraluminal SV-APP-interacting network; and (2) secretase-mediated cleavage within the ISVAID can negatively modulate these interactions. To test functional relevance of this SV-APP-interacting network in SV biology, we have used Ex/TM, a peptide encompassing the ISVAID, to assess its electrophysiological function. Strikingly, Ex/TM caused a decrease in PPF, as well as an increase in mEPSC frequency, but not amplitude and decay time, consistent with a presynaptic mechanism of action. These effects are evident in WT synapses but absent at synapses lacking APP, indicating that Ex/TM acts as a dominant negative inhibitor of APP. Moreover, peptide mapping of the functional segments of the ISVAID by electrophysiological studies are consistent with the hypothesis that $\beta$ and $\alpha$ cleavage of APP may hinder the function of the ISVAID. Together, these results indicate that: (1) the ISVAID hampers the release of excitatory SVs, likely via the interaction with and functional regulation of SV protein; and (2) $\beta$ and $\alpha$ cleavage of the ISVAID may facilitate glutamate release.

The proteomic studies also indicated that SV-APP-interacting networks may be restricted to glutamatergic SV, suggesting that the SV-APP-interacting networks may modulate excitatory but not inhibitory synaptic transmission. Fittingly, we found that the Ex/TM peptide did not significantly alter GABA release.

The data reported here, together with a recent study, suggest that APP may contain both an intraluminal and a cytosolic SVinteracting domain, which modulate glutamatergic release in opposing fashions: glutamate release is hampered by intraluminal interactions but facilitated by cytosolic interactions. These mechanisms of action could act in concert to control physiological functions of APP on neurotransmitter release. Whether these intravesicular interactions can be negatively modulated by $\beta$ - or $\alpha$ cleavage of APP remains to be determined. The evidence that a $\beta$-secretase inhibitor causes strong reduction in the frequency of sEPSC/mEPSC (Filser et al., 2015) and that $\beta$-secretase KO mice show an increase in PPF ratio, which in the author's words is indicative of a reduction in presynaptic release (Wang et al., 2008), are consistent with this hypothesis. However, given the fact that $\beta$-secretase may process several synaptic substrates that may affect synaptic transmission, future experiments will be needed to determine whether these effects are due to inefficient $\beta$-processing of APP. Conversely, the ISVAID-SV protein interactions may affect the downstream processing of APP. Recently, it has been reported that APP is processed in a high molecular weight complex wherein $\gamma$-secretase interacts with $\alpha$ - or $\beta$-secretase to direct the sequential cleavage of APP (Liu et al., 2019). The ISVAID-SV interactions could therefore represent a way in which a fraction of APP is sequestered from or delivered to these high molecular weight complexes for further processing.

\section{References}

Cao X, Südhof TC (2004) Dissection of amyloid-beta precursor proteindependent transcriptional transactivation. J Biol Chem 279:2460124611.

Chamberland S, Topolnik L (2012) Inhibitory control of hippocampal inhibitory neurons. Front Neurosci 6:165.

Checler F, Sunyach C, Pardossi-Piquard R, Sévalle J, Vincent B, Kawarai T, Girardot N, St George-Hyslop P, da Costa CA (2007) The gamma/ epsilon-secretase-derived APP intracellular domain fragments regulate p53. Curr Alzheimer Res 4:423-426.

Cheng X, He P, Lee T, Yao H, Li R, Shen Y (2014) High activities of BACE1 in brains with mild cognitive impairment. Am J Pathol 184:141-147.

Del Prete D, Lombino F, Liu X, D'Adamio L (2014) APP is cleaved by Bace1 in pre-synaptic vesicles and establishes a pre-synaptic interactome, via its intracellular domain, with molecular complexes that regulate presynaptic vesicles functions. PLoS One 9:e108576.

De Strooper B, Voet T (2012) Alzheimer's disease: a protective mutation. Nature 488:38-39.

Fanutza T, Del Prete D, Ford MJ, Castillo PE, D’Adamio L (2015) APP and APLP2 interact with the synaptic release machinery and facilitate transmitter release at hippocampal synapses. Elife 4:e09743.

Filser S, Ovsepian SV, Masana M, Blazquez-Llorca L, Brandt Elvang A, Volbracht C, Müller MB, Jung CK, Herms J (2015) Pharmacological inhibition of BACE1 impairs synaptic plasticity and cognitive functions. Biol Psychiatry 77:729-739.

Fogel H, Frere S, Segev O, Bharill S, Shapira I, Gazit N, O’Malley T, Slomowitz E, Berdichevsky Y, Walsh DM, Isacoff EY, Hirsch JA, Slutsky I (2014) APP homodimers transduce an amyloid-beta-mediated increase in release probability at excitatory synapses. Cell Rep 7:1560-1576.

Freund TF, Buzsáki G (1996) Interneurons of the hippocampus. Hippocampus 6:347-470.

Garringer HJ, Murrell J, D’Adamio L, Ghetti B, Vidal R (2010) Modeling familial British and Danish dementia. Brain Struct Funct 214:235-244.

Gervais FG, Xu D, Robertson GS, Vaillancourt JP, Zhu Y, Huang J, LeBlanc A, Smith D, Rigby M, Shearman MS, Clarke EE, Zheng H, Van Der Ploeg LH, Ruffolo SC, Thornberry NA, Xanthoudakis S, Zamboni RJ, Roy S, Nicholson DW (1999) Involvement of caspases in proteolytic cleavage of Alzheimer's amyloid-beta precursor protein and amyloidogenic A beta peptide formation. Cell 97:395-406.

Giliberto L, Matsuda S, Vidal R, D'Adamio L (2009) Generation and initial characterization of FDD knock in mice. PLoS One 4:e7900.

Groemer TW, Thiel CS, Holt M, Riedel D, Hua Y, Hüve J, Wilhelm BG, Klingauf J (2011) Amyloid precursor protein is trafficked and secreted via synaptic vesicles. PLoS One 6:e18754.

Grønborg M, Pavlos NJ, Brunk I, Chua JJ, Münster-Wandowski A, Riedel D, Ahnert-Hilger G, Urlaub H, Jahn R (2010) Quantitative comparison of glutamatergic and GABAergic synaptic vesicles unveils selectivity for few proteins including MAL2, a novel synaptic vesicle protein. J Neurosci 30:2-12.

Gulisano W, Maugeri D, Baltrons MA, Fà M, Amato A, Palmeri A, D’Adamio L, Grassi C, Devanand DP, Honig LS, Puzzo D, Arancio O (2018) Role of amyloid-beta and tau proteins in Alzheimer's disease: confuting the amyloid cascade. J Alzheimers Dis 64:S611-S631.

Hampel H, Shen Y (2009) Beta-site amyloid precursor protein cleaving enzyme 1 (BACE1) as a biological candidate marker of Alzheimer's disease. Scand J Clin Lab Invest 69:8-12.

Hartl D, May P, Gu W, Mayhaus M, Pichler S, Spaniol C, Glaab E, Bobbili DR, Antony P, Koegelsberger S, Kurz A, Grimmer T, Morgan K, Vardarajan BN, Reitz C, Hardy J, Bras J, Guerreiro R, Balling R, Schneider JG, et al. (2018) A rare loss-of-function variant of ADAM17 is associated with late-onset familial Alzheimer disease. Mol Psychiatry. Advance online publication. Retrieved July 9, 2018. doi:10.1038/s41380-018-0091-8.

Jo SA, Ahn K, Kim E, Kim HS, Jo I, Kim DK, Han C, Park MH (2008) Association of BACE1 gene polymorphism with Alzheimer's disease in Asian populations: meta-analysis including Korean samples. Dement Geriatr Cogn Disord 25:165-169.

Kohli BM, Pflieger D, Mueller LN, Carbonetti G, Aebersold R, Nitsch RM, Konietzko U (2012) Interactome of the amyloid precursor protein APP in brain reveals a protein network involved in synaptic vesicle turnover and a close association with synaptotagmin-1. J Proteome Res 11: 4075-4090.

Liu L, Ding L, Rovere M, Wolfe MS, Selkoe DJ (2019) A cellular complex of 
BACE1 and gamma-secretase sequentially generates abeta from its fulllength precursor. J Cell Biol 218:644-663.

Long JM, Ray B, Lahiri DK (2014) MicroRNA-339-5p down-regulates protein expression of beta-site amyloid precursor protein-cleaving enzyme 1 (BACE1) in human primary brain cultures and is reduced in brain tissue specimens of Alzheimer disease subjects. J Biol Chem 289:5184-5198.

Lu DC, Rabizadeh S, Chandra S, Shayya RF, Ellerby LM, Ye X, Salvesen GS, Koo EH, Bredesen DE (2000) A second cytotoxic proteolytic peptide derived from amyloid beta-protein precursor. Nat Med 6:397-404.

Lundgren JL, Ahmed S, Schedin-Weiss S, Gouras GK, Winblad B, Tjernberg LO, Frykman S (2015) ADAM10 and BACE1 are localized to synaptic vesicles. J Neurochem 135:606-615.

Madeira A, Pommet JM, Prochiantz A, Allinquant B (2005) SET protein (TAF1beta, I2PP2A) is involved in neuronal apoptosis induced by an amyloid precursor protein cytoplasmic subdomain. FASEB J 19:1905-1907.

Matsuda S, Giliberto L, Matsuda Y, Davies P, McGowan E, Pickford F, Ghiso J, Frangione B, D’Adamio L (2005) The familial dementia BRI2 gene binds the Alzheimer gene amyloid-beta precursor protein and inhibits amyloid-beta production. J Biol Chem 280:28912-28916.

Matsuda S, Giliberto L, Matsuda Y, McGowan EM, D’Adamio L (2008) BRI2 inhibits amyloid beta peptide precursor protein processing by interfering with the docking of secretases to the substrate. J Neurosci 28:8668-8676.

Matsuda S, Matsuda Y, Snapp EL, D’Adamio L (2011a) Maturation of BRI2 generates a specific inhibitor that reduces APP processing at the plasma membrane and in endocytic vesicles. Neurobiol Aging 32:1400-1408.

Matsuda S, Tamayev R, D'Adamio L (2011b) Increased AbetaPP processing in familial Danish dementia patients. J Alzheimers Dis 27:385-391.

Milosch N, Tanriöver G, Kundu A, Rami A, François JC, Baumkötter F, Weyer SW, Samanta A, Jäschke A, Brod F, Buchholz CJ, Kins S, Behl C, Müller UC, Kögel D (2014) Holo-APP and G-protein-mediated signaling are required for sAPPalpha-induced activation of the Akt survival pathway. Cell Death Dis 5:e1391.

Nikolaev A, McLaughlin T, O'Leary DD, Tessier-Lavigne M (2009) APP binds DR6 to trigger axon pruning and neuron death via distinct caspases. Nature 457:981-989.

Norstrom EM, Zhang C, Tanzi R, Sisodia SS (2010) Identification of NEEP21 as a ss-amyloid precursor protein-interacting protein in vivo that modulates amyloidogenic processing in vitro. J Neurosci 30: 15677-15685.

Oster-Granite ML, McPhie DL, Greenan J, Neve RL (1996) Age-dependent neuronal and synaptic degeneration in mice transgenic for the $\mathrm{C}$ terminus of the amyloid precursor protein. J Neurosci 16:6732-6741.

Passer B, Pellegrini L, Russo C, Siegel RM, Lenardo MJ, Schettini G, Bachmann M, Tabaton M, D'Adamio L (2000) Generation of an apoptotic intracellular peptide by gamma-secretase cleavage of Alzheimer's amyloid beta protein precursor. J Alzheimers Dis 2:289-301.

Pellegrini L, Passer BJ, Tabaton M, Ganjei JK, D’Adamio L (1999) Alternative, non-secretase processing of Alzheimer's beta-amyloid precursor protein during apoptosis by caspase-6 and -8. J Biol Chem 274: 21011-21016.

Peng J, Kim MJ, Cheng D, Duong DM, Gygi SP, Sheng M (2004) Semiquan- titative proteomic analysis of rat forebrain postsynaptic density fractions by mass spectrometry. J Biol Chem 279:21003-21011.

Puzzo D, Arancio O (2006) Fibrillar beta-amyloid impairs the late phase of long term potentiation. Curr Alzheimer Res 3:179-183.

Puzzo D, Privitera L, Leznik E, Fà M, Staniszewski A, Palmeri A, Arancio O (2008) Picomolar amyloid-beta positively modulates synaptic plasticity and memory in hippocampus. J Neurosci 28:14537-14545.

Puzzo D, Piacentini R, Fà M, Gulisano W, Li Puma DD, Staniszewski A, Zhang H, Tropea MR, Cocco S, Palmeri A, Fraser P, D’Adamio L, Grassi C, Arancio O (2017) LTP and memory impairment caused by extracellular Abeta and Tau oligomers is APP-dependent. Elife 6:e26991.

Shankar GM, Bloodgood BL, Townsend M, Walsh DM, Selkoe DJ, Sabatini BL (2007) Natural oligomers of the Alzheimer amyloid-beta protein induce reversible synapse loss by modulating an NMDA-type glutamate receptor-dependent signaling pathway. J Neurosci 27:2866-2875.

Sisodia SS, St George-Hyslop PH (2002) gamma-secretase, Notch, Abeta and Alzheimer's disease: where do the presenilins fit in? Nat Rev Neurosci 3:281-290.

Sisodia SS, Annaert W, Kim SH, De Strooper B (2001) Gamma-secretase: never more enigmatic. Trends Neurosci 24:S2-S6.

Suh J, Choi SH, Romano DM, Gannon MA, Lesinski AN, Kim DY, Tanzi RE (2013) ADAM10 missense mutations potentiate beta-amyloid accumulation by impairing prodomain chaperone function. Neuron 80:385-401.

Tamayev R, D'Adamio L (2012) Inhibition of gamma-secretase worsens memory deficits in a genetically congruous mouse model of Danish dementia. Mol Neurodegener 7:19.

Tamayev R, Giliberto L, Li W, d'Abramo C, Arancio O, Vidal R, D'Adamio L (2010a) Memory deficits due to familial British dementia BRI2 mutation are caused by loss of BRI2 function rather than amyloidosis. J Neurosci 30:14915-14924.

Tamayev R, Matsuda S, Fà M, Arancio O, D’Adamio L (2010b) Danish dementia mice suggest that loss of function and not the amyloid cascade causes synaptic plasticity and memory deficits. Proc Natl Acad Sci U S A 107:20822-20827.

Tamayev R, Matsuda S, Giliberto L, Arancio O, D’Adamio L (2011) APP heterozygosity averts memory deficit in knockin mice expressing the Danish dementia BRI2 mutant. EMBO J 30:2501-2509.

Tamayev R, Akpan N, Arancio O, Troy CM, D’Adamio L (2012a) Caspase-9 mediates synaptic plasticity and memory deficits of Danish dementia knock-in mice: caspase- 9 inhibition provides therapeutic protection. Mol Neurodegener 7:60.

Tamayev R, Matsuda S, Arancio O, D’Adamio L (2012b) beta- but not gamma-secretase proteolysis of APP causes synaptic and memory deficits in a mouse model of dementia. EMBO Mol Med 4:171-179.

Wang H, Song L, Laird F, Wong PC, Lee HK (2008) BACE1 knock-outs display deficits in activity-dependent potentiation of synaptic transmission at mossy fiber to CA3 synapses in the hippocampus. J Neurosci 28:8677-8681.

Zhou D, Noviello C, D’Ambrosio C, Scaloni A, D'Adamio L (2004) Growth factor receptor-bound protein 2 interaction with the tyrosine-phosphorylated tail of amyloid beta precursor protein is mediated by its $\mathrm{Src}$ homology 2 domain. J Biol Chem 279:25374-25380.

Zucker RS, Regehr WG (2002) Short-term synaptic plasticity. Annu Rev Physiol 64:355-405. 